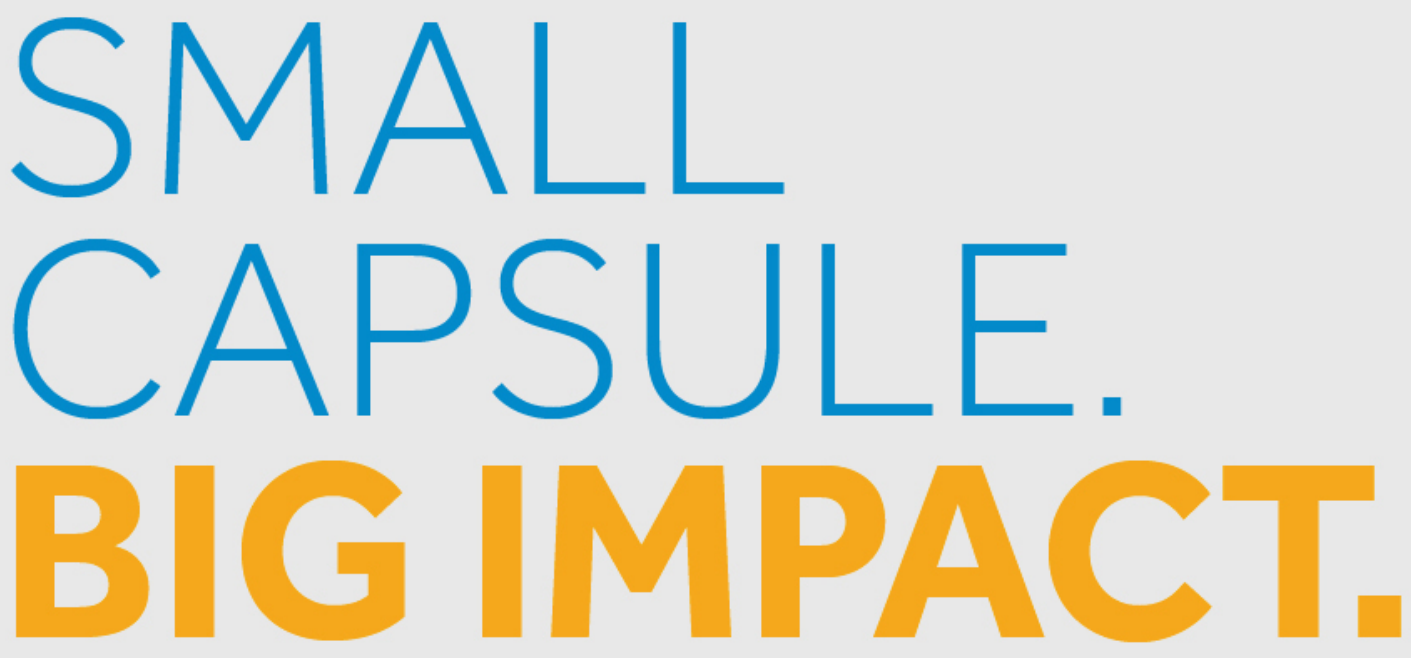

Celebrating 20 years of

PillCam ${ }^{\text {TM }}$ capsule endoscopy

$>$ JOIN THE CELEBRATION

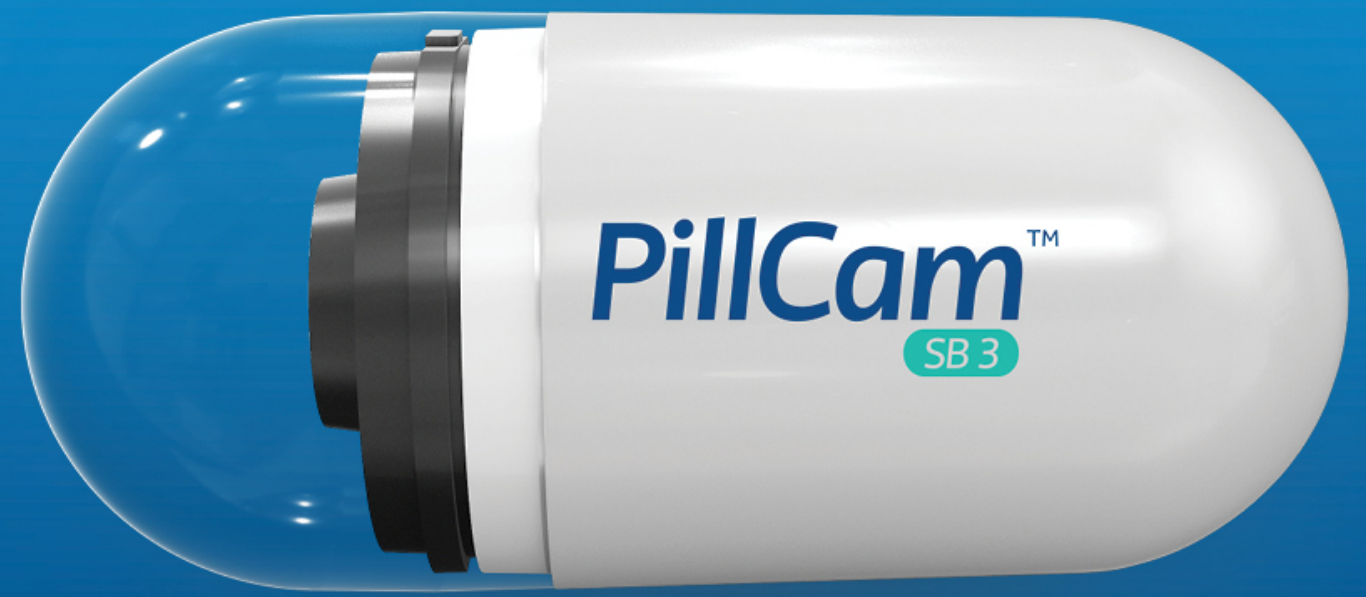

PillCam ${ }^{\text {TM }}$

capsule endoscopy 


\section{United European Gastroenterology (UEG) and European Society for Neurogastroenterology and Motility (ESNM) consensus on functional dyspepsia}

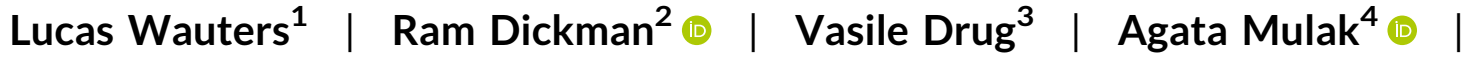 Jordi Serra ${ }^{5}$ | Paul Enck ${ }^{6}$ | Jan Tack ${ }^{1}$ (1) | ESNM FD Consensus Group:} Anna Accarino $^{7}$ | Giovanni Barbara ${ }^{8}$ | Serhat Bor ${ }^{9}$ | Benoit Coffin ${ }^{10}$ | Maura Corsetti $^{11}$ | Heiko De Schepper ${ }^{12}$ | Dan Dumitrascu ${ }^{13}$ | Adam Farmer ${ }^{14}$ | Guillaume Gourcerol ${ }^{15}$ | Goran Hauser ${ }^{16}$ | Trygve Hausken ${ }^{17}$ |

George Karamanolis $^{18}$ | Daniel Keszthelyi ${ }^{19}$ | Carolin Malagelada ${ }^{7}$ | Tomislav Milosavljevic $^{20}$ | Jean Muris ${ }^{21}$ | Colm O'Morain ${ }^{22}$ | Athanassos Papathanasopoulos ${ }^{23}$ | Daniel Pohl ${ }^{24}$ | Diana Rumyantseva ${ }^{25}$ | Giovanni Sarnelli $^{26}$ | Edoardo Savarino ${ }^{27}$ | Jolien Schol ${ }^{1}$ | Arkady Sheptulin ${ }^{25}$ | Annemieke Smet $^{28}$ | Andreas Stengel ${ }^{29,30,31,32}$ | Olga Storonova ${ }^{25}$ | Martin Storr $^{30}$ | Hans Törnblom ${ }^{33}$ | Tim Vanuytsel ${ }^{1}$ | Monica Velosa ${ }^{34}$ | Marek Waluga $^{35}$ | Natalia Zarate ${ }^{36}$ Frank Zerbib ${ }^{37}$

\footnotetext{
${ }^{1}$ Department of Gastroenterology and Hepatology, University Hospitals Leuven, Leuven, Belgium

${ }^{2}$ Division of Gastroenterology, Rabin Medical Center, Beilinson Hospital, Petach Tikwa, Israel

${ }^{3}$ University of Medicine and Pharmacy Gr T Popa lasi and University Hospital St Spiridon, lasi, Romania

${ }^{4}$ Department of Gastroenterology and Hepatology, Wroclaw Medical University, Wroclaw, Poland

${ }^{5}$ University Hospital Germans Trias I Pujol and Centro de Investigación Biomédica en Red de enfermedades Hepáticas y Digestivas (CIBERehd), Badalona, Spain

${ }^{6}$ Department of Internal Medicine VI: Psychosomatic Medicine and Psychotherapy, University Hospital Tübingen, Tübingen, Germany

${ }^{7}$ CIBERehd and Departament de Medicina, Digestive System Research Unit, University Hospital Vall D'Hebron, Barcelona, Spain

${ }^{8}$ Department of Medical and Surgical Sciences, University of Bologna, Bologna, Italy

${ }^{9}$ Division of Gastroenterology, School of Medicine, Ege University, Izmir, Turkey

${ }^{10}$ Université de Paris and AP-HP Hôpital Louis Mourier, Paris, France

${ }^{11}$ NIHR Nottingham Biomedical Research Centre (BRC), Hospitals NHS Trust and the University of Nottingham, Nottingham, UK

${ }^{12}$ Department of Gastroenterology and Hepatology, University Hospital Antwerp, Antwerp, Belgium

${ }^{13}$ 2nd Department of Internal Medicine, Iuliu Hatieganu University of Medicine and Pharmacy, Cluj-Napoca, Romania

${ }^{14}$ Wingate Institute of Neurogastroenterology, Barts and London School of Medicine and Dentistry, Queen Mary University of London, London, UK

${ }^{15}$ Physiology Department, Rouen University Hospital, Rouen, France

${ }^{16}$ Medical Faculty Rijeka, University of Rijeka and Clinical Hospital Centre Rijeka, Rijeka, Croatia

${ }^{17}$ Department of Gastroenterology, Haukeland University Hospital, Bergen, Norway

${ }^{18}$ Gastroentrology Unit, Aretaieio Hospital, National and Kapodistrian University of Athens, Athens, Greece
}

This is an open access article under the terms of the Creative Commons Attribution-NonCommercial-NoDerivs License, which permits use and distribution in any medium, provided the original work is properly cited, the use is non-commercial and no modifications or adaptations are made.

(c) 2021 The Authors. United European Gastroenterology Journal published by Wiley Periodicals LLC on behalf of United European Gastroenterology. 


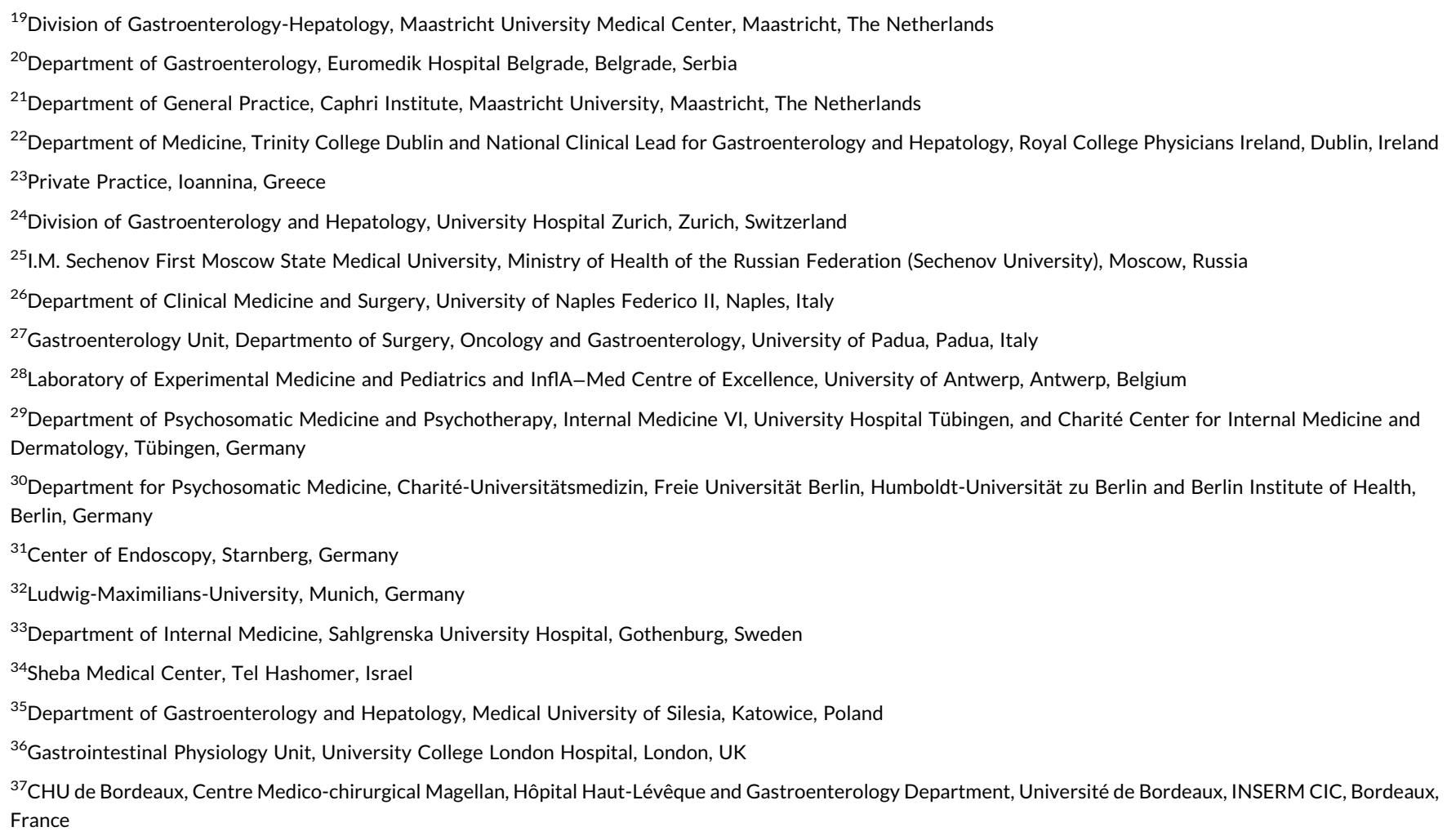

\section{Correspondence}

Jan Tack MD, PhD, Division of

Gastroenterology, University Hospital

Gasthuisberg, Herestraat 49, B-3000 Leuven,

Belgium.

Email: jan.tack@kuleuven.be

\section{Funding information}

United European Gastroenterology, Grant/

Award Number: no number

\begin{abstract}
Background: Functional dyspepsia (FD) is one of the most common conditions in clinical practice. In spite of its prevalence, FD is associated with major uncertainties in terms of its definition, underlying pathophysiology, diagnosis, treatment, and prognosis. Methods: A Delphi consensus was initiated with 41 experts from 22 European countries who conducted a literature summary and voting process on 87 statements. Quality of evidence was evaluated using the grading of recommendations, assessment, development, and evaluation (GRADE) criteria. Consensus (defined as $>80 \%$ agreement) was reached for 36 statements.
\end{abstract}

Results: The panel agreed with the definition in terms of its cardinal symptoms (early satiation, postprandial fullness, epigastric pain, and epigastric burning), its subdivision into epigastric pain syndrome and postprandial distress syndrome, and the presence of accessory symptoms (upper abdominal bloating, nausea, belching), and overlapping conditions. Also, well accepted are the female predominance of FD, its impact on quality of life and health costs, and acute gastrointestinal infections, and anxiety as risk factors. In terms of pathophysiological mechanisms, the consensus supports a role for impaired gastric accommodation, delayed gastric emptying, hypersensitivity to gastric distention, Helicobacter pylori infection, and altered central processing of signals from the gastroduodenal region. There is consensus that endoscopy is mandatory for establishing a firm diagnosis of FD, but that in primary care, patients without alarm symptoms or risk factors can be managed without endoscopy. There is consensus that $H$. pylori status should be determined in every patient with dyspeptic symptoms and $H$. pylori positive patients should receive eradication therapy. Also, proton pump inhibitor therapy is 
considered an effective therapy for FD, but no other treatment approach reached a consensus. The long-term prognosis and life expectancy are favorable.

Conclusions and Inferences: A multinational group of European experts summarized the current state of consensus on the definition, diagnosis and management of FD.

\section{KEYWORDS}

consensus, endoscopy, evidence-based medicine, functional dyspepsia, proton pump inhibitors

\section{Key summary}

\section{Current knowledge}

- Functional dyspepsia is one of the most common conditions encountered in clinical practice.

- There is a lack of guidance for clinicians in guiding diagnosis and treatment of this prevalent condition.

- No treatments are currently approved for the treatment of functional dyspepsia in Europe.

\section{What is new here}

- A Delphi panel consisting of 41 experts from 22 European countries established the level of consensus on 87 statements regarding functional dyspepsia.

- The statements reaching consensus serve to guide clinicians in recognizing, diagnosing and treating FD in clinical practice.

- Endoscopy is mandatory for establishing a firm diagnosis of functional dyspepsia D, but in primary care patients without alarm symptoms or risk factors can be managed without endoscopy.

- Helicobacter pylori status should be determined in every patient with dyspeptic symptoms and $\mathrm{H}$. Pylori positive patients should receive eradication therapy.

- Proton pump inhibitor-therapy is considered an effective therapy for FD, but no other treatment approach reached consensus support.

\section{INTRODUCTION}

Functional dyspepsia (FD), defined by the presence of recurrent or chronic epigastric symptoms in the absence of organic disease likely to explain them, is one of the most common conditions seen in clinical practice. $^{1,2}$ In spite of its prevalence, FD is associated with major uncertainties, as definitions and the symptom spectrum of FD have evolved over time, ${ }^{3}$ the differential diagnosis is very broad, ${ }^{1}$ the optimal diagnostic work-up has not been defined, ${ }^{4,5}$ and there is a lack of available treatments with established efficacy., ${ }^{6,7}$

The aim of this project was to develop a European consensus on the definition, pathophysiological concepts, diagnosis, management, and prognosis of FD. The results of this consensus can offer the clinician guidance in diagnosing and managing FD patients to optimize clinical outcomes.

\section{METHODS}

The European Society for Neurogastroenterology and Motility (ESNM) initiated a Delphi process, funded by United European Gastroenterology, to develop consensus statements on different aspects of FD in collaboration with other European societies. The Delphi approach, which combines the principles of evidence-based medicine, supported by systematic literature reviews and a voting process, aims at determining consensus for complex problems in medicine for which evidence from controlled trials is lacking. ${ }^{8}$

The principal steps in the process were (1) selection of a working group of seven ESNM members with expertise in FD and/or Delphi consensus processes; (2) selection of a European Consensus Group consisting of experts in FD from different European countries, recruited through the ESNM board and through UEG Sister Societies; (3) drafting of statements allowing to evaluate the current knowledge on FD; (4) systematic literature reviews to identify evidence to support each statement; (5) two rounds of repeated voting of the statements and voting discussion until a stable level of consensus voting was reached; and (6) grading of the strength of evidence using accepted criteria.

For the Consensus Group, ESNM board members nominated experts from their respective national societies for participation, and the UEG Sister Societies (EAGEN, EHSMG, and ESPCG) nominated additional experts. A total of 41 experts from 22 European countries agreed to participate. The members had a background of expertise in gastroenterology, general practice, Helicobacter pylori infection or gastrointestinal motility. All members submitted a conflict of interest statement by December 2018.

The seven-member Core Group drafted and finalized a list of 75 statements covering several aspects of FD. The finalized list was evaluated in the first voting round by all members in the second quarter of 2019, where each member indicated the degree of agreement for the statement using a 6-point Likert scale (Table 1). 
TABLE 1 Six-point Likert scale

\begin{tabular}{ll} 
Point & Description \\
\hline A+ & Agree strongly \\
\hline A & Agree with minor reservation \\
A- & Agree with major reservation \\
D- & Disagree with minor reservation \\
\hline D & Disagree with major reservation \\
D+ & Disagree strongly \\
\hline
\end{tabular}

Participants were blinded to the votes of other participants and also gave feedback on the clarity of the statement and made suggestions for adapting or splitting the statements into two or more questions, or for adding additional statements on a given topic. The Core Group adjusted the statement list, generating a total of 87 statements, and subdivided the Guideline Group members into 12 working groups with 3-4 members each. Each working group was allocated statements for which they needed to conduct a systematic literature search using several relevant keywords and provide narrative substantiation of the statements. The literature review and references were made available on a share-point server, accessible to all members. This was finalized by the Summer of 2019 , followed by a voting round in which each statement was presented with the evidence summary. The available members of the Guideline Group met in September 2019 at the occasion of the ESNM meeting in Lisbon and in October 2019 at the UEG week in Barcelona to discuss statements and voting outcomes. A final voting round was conducted between both meetings, focusing on statements that were adapted based on the evaluation at the ESNM meeting. Throughout the process, all votes were mutually anonymous and blinded.

When $80 \%$ of the Consensus Group agreed $(A+$ or $A)$ with a statement, this was defined as consensus. The strength of evidence for each statement was scored using the GRADE system (Table 2). ${ }^{9}$ After the final voting round (summarized in Table 3), the manuscript was drafted and circulated for the final approval by the participants. The references cited in this chapter are only a selection of the articles reviewed in each area, chosen to clarify the discussion. A final meeting planned in October 2020 was canceled because of the COVID-19 pandemic.

\section{RESULTS}

1. Definitions and symptom descriptors

1.1 Dyspepsia refers to a symptom or set of symptoms that is (are) considered to originate from the gastroduodenal region. STATEMENT ENDORSED, overall agreement 98\%: A+ 78\%, A 20\%, A- 0\%, D- 2\%, D 0\%, D+ 0\%.

GRADE B

1.2 Early satiation, postprandial fullness, epigastric pain, and epigastric burning are the cardinal dyspeptic symptoms as defined by Rome IV.
STATEMENT ENDORSED, overall agreement 98\%: A+ 83\%, A $15 \%, A-0 \%, D-2 \%, D$, D + 0\%.

GRADE B

1.3 Functional dyspepsia is a condition characterized by chronic dyspeptic symptoms in the absence of organic, systemic, or metabolic condition(s) that is (are) likely to explain symptoms STATEMENT ENDORSED, overall agreement 93\%: $A+68 \%, A$ 25\%, A- 7\%, D- 0\%, D 0\%, D+ 0\%:

GRADE A

1.4 The vast majority of patients with dyspeptic symptoms and no alarm symptoms in the general population are identified as functional dyspepsia after investigation (if this would be done).

STATEMENT ENDORSED, overall agreement 93\%: A+ 66\%, A $27 \%, A-2 \%$, D- 0\%, D 5\%, D+ 0\%:

GRADE A

1.5 Two main subtypes of functional dyspepsia are distinguished which may overlap: postprandial distress syndrome (PDS) characterized by meal-induced symptoms (early satiation, postprandial fullness) and epigastric pain syndrome (EPS), with epigastric pain and/or epigastric burning not necessarily associated with a meal.

STATEMENT ENDORSED, overall agreement 98\%: A+ 78\%, A $20 \%, A-2 \%$, D- 0\%, D 0\%, D+ 0\%:

GRADE B

1.6 Dyspeptic symptoms often coexist with other symptoms such as bloating in the upper abdomen, nausea, and belching. STATEMENT ENDORSED, overall agreement 98\%: A+ 73\%, A 25\%, A- 0\%, D- 2\%, D 0\%, D+ 0\%:

GRADE A

1.7 Bloating or visible distention in the upper abdomen is a dyspeptic symptom.

STATEMENT NOT ENDORSED, overall agreement 61\%: A+ $27 \%$, A 34\%, A- 29\%, D- 0\%, D 5\%, D+ 5\%: $\quad$ GRADE B

1.8 The use of pictograms helps to characterize the presence and nature of dyspeptic symptoms.

STATEMENT NOT ENDORSED, overall agreement 76\%: A+ 27\%, A 49\%, A- 24\%, D- 0\%, D 0\%, D+ 0\%: GRADE C

1.9 Typical reflux symptoms (heartburn, regurgitation) often coexist with dyspeptic symptoms in the general population: STATEMENT ENDORSED, overall agreement 98\%: A+ 56\%, A $42 \%, A-2 \%, D-0 \%, D$ 0\%, D+ 0\%:

GRADE A

1.10 Gastroesophageal reflux disease may be distinguished from functional dyspepsia using dedicated questionnaires or good history taking.

STATEMENT NOT ENDORSED, overall agreement 46\%: A+ 14\%, A $32 \%, A-24 \%$, D- 10\%, D 17\%, D+ 2\%. GRADE C

1.11 Irritable bowel syndrome often coexists with functional dyspepsia.

STATEMENT ENDORSED, overall agreement 95\%: A+ 73\%, A $22 \%, A-5 \%$, D- 0\%, D 0\%, D+ 0\%: GRADE A

The definition of dyspepsia and FD has seen major evolutions over time. While early definitions included esophageal symptoms such as heartburn, as well as nausea, vomiting, and belching within the dyspeptic symptom complex, the Rome III and Rome IV consensus have significantly narrowed the symptom profile., ${ }^{1,3,10}$ The recent Rome IV consensus, which defined dyspepsia as the 
TABLE 2 Grading of recommendations assessment, development and evaluation system ${ }^{9}$

\begin{tabular}{|c|c|c|}
\hline Code & Quality of evidence & Definition \\
\hline B & Moderate & $\begin{array}{l}\text { Further research is likely to have an important impact on our confidence in the estimate of effect and may change } \\
\text { the estimate. } \\
\text { - One high-quality study } \\
\text { - Several studies with some limitations }\end{array}$ \\
\hline C & Low & $\begin{array}{l}\text { Further research is very likely to have an important impact on our confidence in the estimate of effect and is likely } \\
\text { to change the estimate. } \\
\text { - One or more studies with severe limitations }\end{array}$ \\
\hline
\end{tabular}

presence of chronic symptoms thought to originate from the gastroduodenal region, is well accepted..$^{1}$ According to this consensus, the four cardinal dyspeptic symptoms are troublesome postprandial fullness, early satiation, epigastric pain, and nonradiating epigastric burning. ${ }^{1}$

FD is defined as the presence of chronic dyspeptic symptoms in the absence of organic disease that readily explains the symptoms. ${ }^{1}$ Symptoms do not reliably distinguish between functional and organic dyspepsia. ${ }^{1,12}$ Consequently, in clinical practice, upper endoscopy is regularly performed to rule out organic causes. The prevalence of clinically significant endoscopic findings in subjects with uninvestigated dyspepsia is low, but the high number of affected patients is relevant. Less than $10 \%$ of patients have a peptic ulcer, and less than $1 \%$ have gastroesophageal cancer. ${ }^{4}$ Thus, based on the endoscopic findings, a systematic review and meta-analysis found that more than $70 \%$ of subjects with dyspeptic symptoms qualify for a diagnosis of FD. ${ }^{4}$

Besides the four cardinal symptoms, nausea, belching, and upper abdominal bloating are often found in FD patients and are considered adjunctive features of the FD spectrum. ${ }^{1}$ Their presence may reflect common pathophysiological mechanisms such as altered motility or hypersensitivity. ${ }^{1,7}$

The Rome IV criteria stress that heartburn is not a dyspeptic symptom but may often coexist with FD and that the presence of heartburn should not lead to the exclusion of FD as diagnosis. ${ }^{1,3}$ Overall, one-third of FD patients also experience typical symptoms of gastroesophageal reflux disease (GERD). ${ }^{13}$ It seems that, in cases of overlap between FD and GERD, FD is often underestimated, favoring the diagnosis of GERD. ${ }^{14}$ The substantial overlap of core symptoms of GERD and FD persists, regardless of the use of objective tools or evidence from upper endoscopies or esophageal $\mathrm{pH}$ studies. ${ }^{12,14}$ Thus, separating out GERD and FD based on questionnaires and history taking alone can be quite difficult, if not impossible. ${ }^{13,15}$ In addition, non-acid-related conditions such as functional heartburn frequently overlap with FD. ${ }^{13,16}$ Irritable bowel syndrome (IBS) is another symptomatic condition which frequently overlaps with FD. ${ }^{17}$ The high rate of overlap between FD and conditions like IBS or GERD may be explained by common etiological risk factors (e.g., acute infectious gastroenteritis, psychological disturbances) and pathophysiological mechanisms (e.g., visceral hypersensitivity, altered motility, etc.). ${ }^{13,15-17}$ Severity and impact of symptoms are higher in those with overlapping conditions. ${ }^{40}$

Over time, several subdivisions of the dyspeptic symptom pattern have also been proposed. ${ }^{1,3,10}$ According to the Rome III consensus, and refined in Rome IV, two subgroups are identified within FD: the PDS and the EPS. ${ }^{1,10}$ The PDS subgroup is characterized by symptom triggered or aggravated by a meal and includes postprandial fullness, early satiation, and other postprandial symptoms. The EPS subtype is defined by meal-unrelated symptoms, such as epigastric pain and epigastric burning. ${ }^{1}$ The existence of these subtypes in the general population is supported by epidemiological data. ${ }^{3}$ With the Rome III definitions, a major overlap between EPS and PDS was found, but this is substantially decreased with the Rome IV update. ${ }^{1,3,10,11,40}$

Assessing the presence of cardinal and accessory symptoms requires an accurate understanding of symptom descriptors by the patient. It may be difficult for patients to distinguish upper gastrointestinal symptoms based on verbal descriptors alone, but adding pictograms to verbal descriptors significantly improves the accuracy of symptom reporting by FD patients. ${ }^{18}$ However, as this was done in 
TABLE 3 All statements with endorsement and references

\section{Statement}

1.1. Dyspepsia refers to a symptom or set of symptoms that is (are) considered to originate from the gastroduodenal region.

1.2. Early satiation, postprandial fullness, epigastric pain, and epigastric burning are the cardinal dyspeptic symptoms as defined by Rome IV.

1.3. Functional dyspepsia (FD) is a condition characterized by chronic dyspeptic symptoms in the absence of organic, systemic or metabolic condition(s) that is (are) likely to explain symptoms.

1.4. The vast majority of patients with dyspeptic symptoms and no alarm symptoms in the general population is identified as FD after investigation (if this would be done).

1.5. Two main subtypes of FD are distinguished which may overlap: postprandial distress syndrome (PDS) characterized by meal-induced symptoms (early satiation, postprandial fullness) and epigastric pain syndrome (EPS), with epigastric pain and/or epigastric burning not necessarily associated with a meal.

1.6. Dyspeptic symptoms often co-exist with other symptoms such as bloating in the upper abdomen, nausea and belching.

1.7. Bloating or visible distention in the upper abdomen is a dyspeptic symptom.

1.8. The use of pictograms helps to characterize the presence and nature of dyspeptic symptoms.

1.9. Typical reflux symptoms (heartburn, regurgitation) often co-exist with dyspeptic symptoms in the general population.

1.10. Gastro-esophageal reflux disease may be distinguished from FD using dedicated questionnaires or good history taking.

1.11. Irritable bowel syndrome often coexists with FD.

2.1. (Functional) dyspepsia occurs at all ages but the highest incidence is in the middle age.

2.2.(Functional) dyspepsia is more prevalent in women than men

2.3. Acute GI infection is a risk factor for development of FD.

2.4. NSAID intake is a risk factor for development of FD.

2.5. Antibiotic therapy is a risk factor for development of FD.

2.6. Anxiety is a risk factor for development of FD

2.7. Depression is a risk factor for development of FD.

2.8. Smoking is a risk factor for development of FD.

3.1. FD is a major source of healthcare costs.

3.2. FD is a major source of self-costs to patients.

3.3. FD is an important source of loss of work productivity.

3.4. FD is associated with a significant decrease in quality of life.

3.5. FD is associated with psychosocial co-morbidities such as anxiety and depression

3.6. Weight loss can be consequence of FD

3.7. In case of weight loss, eating disorders must be ruled out.

3.8. Healthcare consulting behavior in FD is driven by symptom severity and impact.

3.9. Healthcare consulting behavior in FD is driven by psychosocial comorbidity.

3.10. Healthcare consulting behavior in FD is driven by access to the healthcare system.

4.1. Dietary factors underlie symptom generation in FD.

4.2. H. pylori is a cause of symptoms in a subgroup of patients with dyspepsia and normal endoscopy.

$\begin{array}{lll}\text { Endorsement } & \begin{array}{l}\text { Grade of } \\ \text { Evidence }\end{array} & \text { References } \\ \text { Yes } & \text { B } & 1-4 \\ \text { Yes } & \text { B } & 1-4 \\ \text { Yes } & \text { A } & 1-4\end{array}$

Yes

Yes

Yes

No

No

Yes

No

Yes

No

Yes

Yes

No

No

Yes

No

No

Yes

Yes

Yes

Yes

Yes

Yes

No

Yes

Yes

No

No

Yes
A

B
1,4

$1,3,10,11$
A

A

1,7

C

B

C

$1,10,11$

18

A

C

12-16

12-16

c

17

B 2,19-22

A

2,19-22

23-27

28-31

C

32

33-48

33-48

49-54

55-58

B

55

$56,57,59$

A

60-62

A

$33-46,48$

63-67

C

63-67

B

57,68-70

B

36,71

B

C

$68,70,72$

57,73-79

B

80-82 
TABLE 3 (Continued)

\section{Statement}

4.3. Impaired gastric accommodation is a pathophysiological mechanism in FD.

4.4. Delayed gastric emptying is a pathophysiological mechanism in FD.

4.5. Rapid gastric emptying is a pathophysiological mechanism in FD.

4.6. Hypersensitivity to gastric distention is a pathophysiological mechanism in FD.

4.7. Duodenal mucosal alterations are a pathophysiological mechanism in FD.

4.8. Altered gastric acid secretion is a pathophysiological mechanism in FD.

4.9. Altered release of peptide hormones is a pathophysiological mechanism in FD.

4.10. Increased sensitivity to duodenal luminal content is a pathophysiological mechanism in FD.

4.11. Altered duodenal microbiota composition is a pathophysiological mechanism in FD.

4.12. Impaired vagus nerve function is a pathophysiological mechanism in FD.

4.13. Anxiety and stress are pathophysiological mechanisms in FD.

4.14. Depression is a pathophysiological mechanism in FD.

4.15. Disordered central processing of incoming signals from the gastroduodenal region is a pathophysiological mechanism in FD.

4.16. Genetic factors determine the susceptibility to FD.

5.1. Upper $\mathrm{Gl}$ endoscopy is mandatory for establishing a diagnosis of FD.

5.2. In primary care, uninvestigated dyspepsia can be managed without endoscopy if there are no alarm of risk factors.

5.3. Upper $\mathrm{Gl}$ endoscopy is mandatory if there are alarm symptoms or risk factors.

5.4. Screening blood test are useful when considering a diagnosis of FD.

5.5. Every patient with dyspeptic symptoms should be tested for $H$. pylori (non-invasively or at gastroscopy).

5.6. Patients with dyspepsia and $H$. pylori positive gastritis should be considered to have FD just if symptoms persist 6 to 12 months after H. pylori eradication.

5.7. Patients with dyspepsia and HP negative gastritis should be considered to have FD.

5.8. FD should be subdivided into EPS and PDS for further diagnostic and therapeutic approach.

5.9. Upper abdominal ultrasound is useful when considering a diagnosis of FD.

5.10. A gastric emptying test is useful when considering a diagnosis of FD.

5.11. Esophageal $\mathrm{pH}$ monitoring is useful in FD to rule out GERD.

5.12. Increased duodenal eosinophil count is a marker of FD.

5.13. Impaired nutrient volume tolerance is a marker of FD.

6.1. Dietary adjustment improves symptoms in FD.

6.2. H. pylori positive FD patients should receive eradication therapy.

6.3. PPI therapy is the most appropriate initial therapy for FD.

6.4. PPI therapy is an effective therapy for FD.

6.5. PPI therapy is most effective for EPS.

6.6. Prokinetic therapy is the most appropriate initial therapy for FD.

6.7. Prokinetic therapy is an effective therapy for FD.

6.8. Prokinetic therapy is most effective for PDS.

Endorsement
Yes
Yes
No
Yes
No
No
No
No

Grade of

Evidence

B

References

B

C

$63,67,83-93$

91,93-102

$99,101,102$

B

$64,91,100-108$

B

109-117

C

118-120

C

121-124

C

127-130

No
No
No
No
Yes

No
Yes
Yes

C

131,132

C

133-138

B

33-48

B

33-46,48

C

139-144

C

145-148

A

1,10,149-151

A

149-151

Yes

A

1,10,149-151

No

Yes

B

A

152

$1,10,81,149$,

$150,153,154$

Yes

B

$1,81,155$

Yes

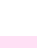

Yes

B

1,81,155

B

3,11,40,156-162

No

No

No

No

No

No

Yes

B

$1,150,165,166$

B

1,91,150,167,168

B

13,169-171

C

172

B

63,67,86,173-176

C

57,73-79

A

$1,81,150,160,177$

B

150,178-186

Yes

A

150,178-186

$150,177,186$

C

150,187-189

C

150,187-189

B

B

150,187-189 
TABLE 3 (Continued)

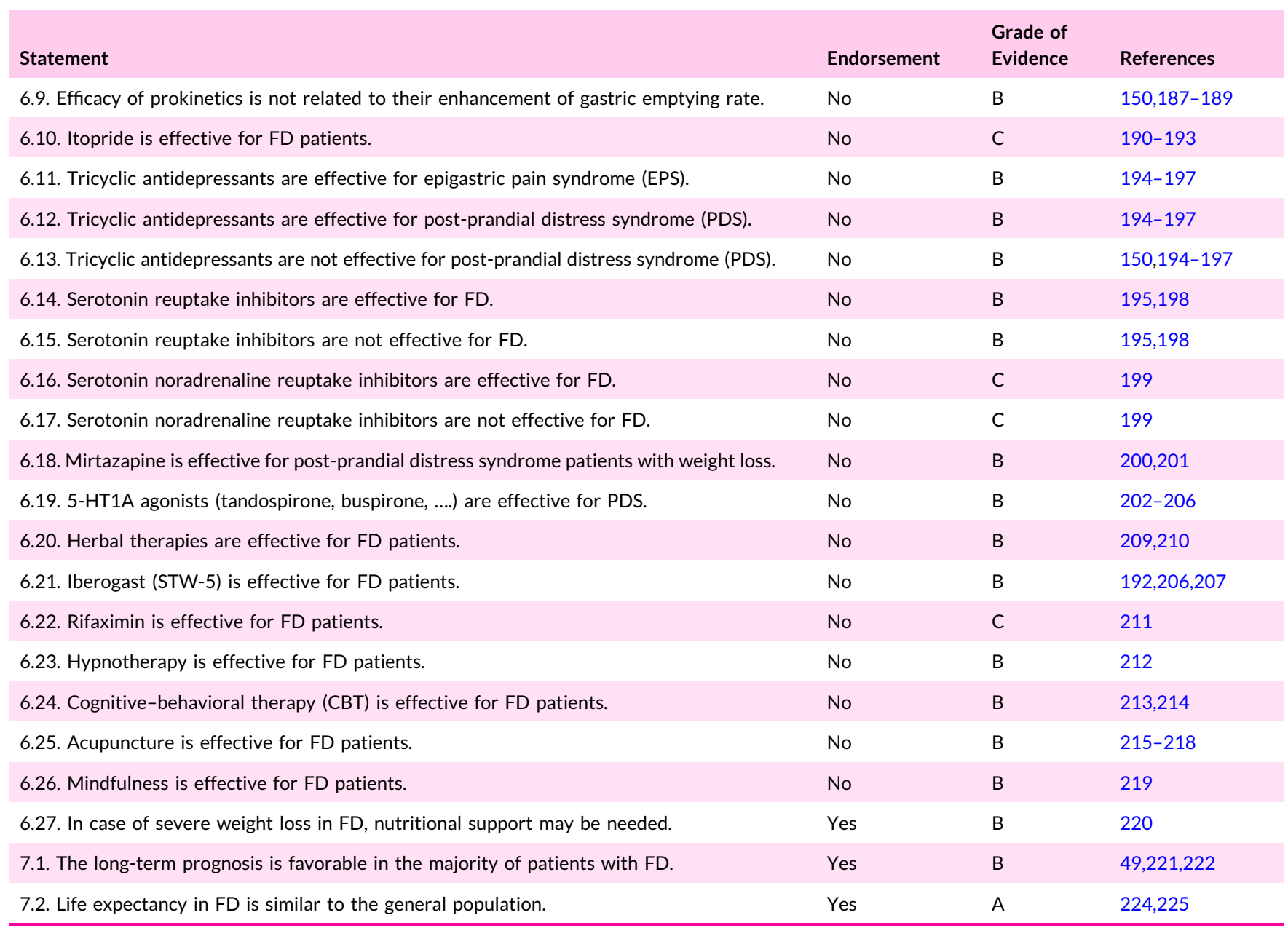

a specific context (tertiary care, Belgium), confirmatory studies in a different medical and cultural-linguistic setting are needed.

2. Epidemiology and risk factors

2.1 (Functional) Dyspepsia occurs at all ages but the highest incidence is in the middle age.

STATEMENT NOT ENDORSED, overall agreement 73\%: A+ $24 \%$, A $49 \%$, A- 24\%, D- 2\%, D 0\%, D+ 0\%. GRADE B

2.2 (Functional) Dyspepsia is more prevalent in women than me. STATEMENT ENDORSED, overall agreement 83\%: A+ 51\%, A $32 \%, A-15 \%, D-0 \%, D 3 \%, D+0 \%$.

GRADE A

2.3 Acute gastrointestinal infection is a risk factor for development of functional dyspepsia.

STATEMENT ENDORSED, overall agreement 90\%: A+ 54\%, A 36\%, A- 5\%, D- 0\%, D 5\%, D+ 0\%.

GRADE A

2.4 NSAID intake is a risk factor for development of functional dyspepsia.

STATEMENT NOT ENDORSED, overall agreement 61\%: A+ $20 \%$, A $41 \%$, A- 20\%, D- 0\%, D 17\%, D+ 2\%. GRADE C

2.5 Antibiotic therapy is a risk factor for development of functional dyspepsia.

STATEMENT NOT ENDORSED, overall agreement 37\%: A+ $5 \%$, A 32\%, A- 32\%, D- 7\%, D 24\%, D+ 0\%.

GRADE C
2.6 Anxiety is a risk factor for development of functional dyspepsia.

STATEMENT ENDORSED, overall agreement 93\%: A+ 34\%, A 59\%, A- 7\%, D- 0\%, D 0\%, D+ 0\%.

GRADE A

2.7 Depression is a risk factor for development of functional dyspepsia.

STATEMENT NOT ENDORSED, overall agreement 76\%: A+ $27 \%$, A $49 \%$, A- 20\%, D- 2\%, D 2\%, D+ 0\%.

GRADE B

2.8 Smoking is a risk factor for development of functional dyspepsia.

STATEMENT NOT ENDORSED, overall agreement 37\%: A+ $7 \%$, A $30 \%, A-46 \%, D-2 \%$, D 15\%, D+ 0\%. GRADE C

Approximately $10 \%$ of the adult population fulfills symptombased Rome IV criteria for (uninvestigated) FD, and its prevalence appears to disappear with increasing age. ${ }^{2,19}$ In several studies, the peak incidence of FD seems to occur in the forties or fifties age segment. ${ }^{19-22}$ A recent metA-analysis including 55 studies revealed a slightly higher pooled prevalence of dyspepsia in women compared with men. ${ }^{19}$ The Rome Global Epidemiology Study, which used the most uniform criteria and approach, showed a significantly higher prevalence of (uninvestigated) Rome IV FD in women compared to men. ${ }^{2}$ 
Acute gastroenteritis is associated with an increased risk of FD, with an estimated mean prevalence of $9.6 \%$ in adults. ${ }^{23}$ Among pathogens suggested to be associated with post-infectious FD (PIFD) are Norovirus, Giardia lamblia, Salmonella spp., Escherichia coli O157, and Campylobacter spp. ${ }^{24-26} \mathrm{H}$. pylori does not seem to be a cause of PI-FD. ${ }^{23,27}$

Nonsteroidal anti-inflammatory drug (NSAID) use has been identified as a risk factor for dyspepsia in two population-based studies. $^{28,29}$ It has been suggested that the development of dyspeptic symptoms during treatment with NSAIDs could be linked to alterations in gastric mechanosensory function. ${ }^{30}$ However, NSAID intake appears to be most relevant to uninvestigated dyspepsia. ${ }^{31}$ Data supporting the role of drugs other than NSAIDs in the pathogenesis of dyspepsia in the general population are lacking. $A$ nested case-control study in Olmsted County suggested that treatment with antibiotics for a non-gastrointestinal infection was associated with the development of functional gastrointestinal disorders (FGIDs), but this needs confirmation in other cohorts. ${ }^{32}$

Several cross-sectional and population-based studies have observed that anxiety is frequently associated with FD. ${ }^{33-46}$ Some longitudinal studies have shown that mood disorders may precede dyspeptic symptoms and thus predispose to FD. ${ }^{39,41-43}$ Similarly, crosssectional and population-based studies have observed that depression is frequently encountered in patients with FD. ${ }^{33,35-40,43-45,47,48}$ However, the Kalixanda study, an important cross-sectional study carried out in a large sample of patients and its longitudinal 10-year follow-up investigation, failed to find a clear association between depression and the risk for development of FD. ${ }^{41,42}$

Population- and endoscopy-based studies suggested an association between smoking and FD. ${ }^{20,49-51}$ In contrast, other populationbased studies failed to find an association after adjustment for confounders such as age, gender, and drugs. ${ }^{52-54}$

3. Impact of functional dyspepsia

3.1 Functional dyspepsia is a major source of healthcare costs. STATEMENT ENDORSED, overall agreement 98\%: A+ 78\%, A $20 \%, A-2 \%$, D- 0\%, D 0\%, D+ 0\%.

GRADE A

3.2 Functional dyspepsia is a major source of self-costs to patients.

STATEMENT ENDORSED, overall agreement 93\%: A+ 64\%, A $29 \%, A-7 \%$, D- 0\%, D 0\%, D+ 0\%.

GRADE B

3.3 Functional dyspepsia is an important source of loss of work productivity.

STATEMENT ENDORSED, overall agreement 88\%: A+ 46\%, A $42 \%, A-10 \%, D-2 \%$, D 0\%, D+ 0\%.

GRADE B

3.4 Functional dyspepsia is associated with a significant decrease in quality of life.

STATEMENT ENDORSED, overall agreement 100\%: A+ 80\%, A 20\%, A- 0\%, D- 0\%, D 0\%, D+ 0\%.

GRADE A

3.5 Functional dyspepsia is associated with psychosocial comorbidities such as anxiety and depression.

STATEMENT ENDORSED, overall agreement 100\%: A+ 61\%, A 39\%, A- 0\%, D- 0\%, D 0\%, D+ 0\%. GRADE A
3.6 Weight loss can be consequence of FD.

STATEMENT ENDORSED, overall agreement 90\%: A+ 43\%, A $47 \%, A-8 \%$, D- 0\%, D 2\%, D+ 0\%.

GRADE B

3.7 In case of weight loss, eating disorders must be ruled out.

STATEMENT NOT ENDORSED, overall agreement 73\%: A+ $36 \%$, A 37\%, A- 19\%, D- 0\%, D 7\%, D+ 0\%. GRADE C

3.8 Healthcare consulting behavior in functional dyspepsia is driven by symptom severity and impact.

STATEMENT ENDORSED, overall agreement 93\%: A+ 42\%, A 51\%, A- 7\%, D- 0\%, D 0\%, D+ 0\%.

GRADE B

3.9 Healthcare consulting behavior in functional dyspepsia is driven by psychosocial comorbidity.

STATEMENT ENDORSED, overall agreement $80 \%$ : A+ 29\%, A 51\%, A- 20\%, D- 0\%, D 0\%, D+ 0\%.

GRADE B

3.10 Healthcare consulting behavior in functional dyspepsia is driven by access to the healthcare system.

STATEMENT NOT ENDORSED, overall agreement 71\%: A+ $17 \%$, A $54 \%$, A- 19\%, D- 0\%, D 7\%, D+ 0\%.

GRADE B

Studies conducted in several parts of the world have shown that FD is associated with significantly elevated health expenses related to medical consultations, diagnostic tests, and therapeutic measures. ${ }^{55-58}$ In addition, FD patients incur both direct and indirect costs driven by over-the-counter medications, alternative therapies, medical consultations, and co-financed treatments, as well as the cost of dietary modifications. ${ }^{55}$ Studies conducted in several parts of the world report that FD patients have increased absenteeism, and reduced productivity at work compared to healthy subjects. ${ }^{56,57,59}$

Multiple studies have shown that FD is associated with a reduction in quality of life. Factors found to be related to a greater reduction in quality of life are anxiety and depression, advanced age, female sex, severity of symptoms, and low or intermediate cultural level. $^{60-62}$

Several cross-sectional studies have shown that FD frequently coexists with anxiety and depression and that the severity of symptoms correlates with scores on psychopathology questionnaires. ${ }^{33-46}$ Furthermore, psychosocial factors, such as depression, history of childhood abuse, and somatization, have shown to contribute to symptom severity more than the degree of gastric sensorimotor dysfunction. ${ }^{38}$

Weight loss occurs in a large subset of subjects with dyspeptic symptoms and is closely associated with symptoms of early satiation as well as epigastric pain, both at the population level and in tertiary care patients. ${ }^{63-66}$ Important determinants of weight loss in FD are impaired accommodation and decreased nutrient volume tolerance. $^{63,67}$

Although dyspepsia affects approximately $10 \%$ of the general population, only half of these ever consult a doctor for their symptoms. Dyspeptic subjects who seek healthcare attention have more severe, frequent, and persistent dyspepsia symptoms. ${ }^{57,68-70}$ In addition, dyspeptic patients with high scores on anxiety and depression questionnaires report higher consultation rates than 
those with lower scores, indicating that psychosocial factors also influence healthcare-seeking behavior. ${ }^{36,71} \mathrm{~A}$ longitudinal study also found that anxiety or depression precedes dyspepsia among consulters in a larger proportion than in non-consulters, confirming that basal psychosocial comorbidity is associated with healthcare seeking. ${ }^{71}$ Consultation rates for dyspepsia vary widely between countries and regions, suggesting that access to the healthcare system may influence healthcare-seeking behavior. ${ }^{70}$ However, differences in healthcare-consulting behavior are also modulated by socioeconomic status. Several studies have shown that low socioeconomic status is associated with higher consultation rates for dyspepsia. ${ }^{68,72}$

4. Pathophysiology of functional dyspepsia

4.1 Dietary factors underlie symptom generation in functional dyspepsia.

STATEMENT NOT ENDORSED, overall agreement 51\%: $A+24 \%$, A $27 \%, A-34 \%, D-2 \%$, D $10 \%$, D+ $2 \%$.

GRADE C

4.2 H. pylori is a cause of symptoms in a subgroup of patients with dyspepsia and normal endoscopy.

STATEMENT ENDORSED, overall agreement 81\%: $A+37 \%$, A $44 \%, A-17 \%, D-2 \%, D$ 0\%, D+ $0 \%$.

GRADE B

4.3 Impaired gastric accommodation is a pathophysiological mechanism in functional dyspepsia.

STATEMENT ENDORSED, overall agreement 93\%: A+ 51\%, A 42\%, A- 7\%, D- 0\%, D 0\%, D+ 0\%.

GRADE B

4.4 Delayed gastric emptying is a pathophysiological mechanism in functional dyspepsia.

STATEMENT ENDORSED, overall agreement 85\%: A+ 39\%, A 46\%, A- 12\%, D- 0\%, D 2\%, D+ 0\%.

GRADE B

4.5 Rapid gastric emptying is a pathophysiological mechanism in functional dyspepsia.

STATEMENT NOT ENDORSED, overall agreement 32\%: A+ $2 \%$, A $30 \%, A-46 \%, D-5 \%, D 15 \%, D+2 \% . \quad$ GRADE C

4.6 Hypersensitivity to gastric distention is a pathophysiological mechanism in functional dyspepsia.

STATEMENT ENDORSED, overall agreement 93\%: A+ 63\%, A 30\%, A- 7\%, D- 0\%, D 0\%, D+ 0\%.

GRADE B

4.7 Duodenal mucosal alterations are a pathophysiological mechanism in functional dyspepsia.

STATEMENT NOT ENDORSED, overall agreement 76\%: A+ $17 \%$, A 59\%, A- 20\%, D- 2\%, D 0\%, D+ 2\%. GRADE B

4.8 Altered gastric acid secretion is a pathophysiological mechanism in functional dyspepsia.

STATEMENT NOT ENDORSED, overall agreement 29\%: A+ 7\%, A $22 \%$, A- 32\%, D- 7\%, D 32\%, D+ 0\%. GRADE C

4.9 Altered release of peptide hormones is a pathophysiological mechanism in functional dyspepsia.

STATEMENT NOT ENDORSED, overall agreement 24\%: A+ 7\%, A $17 \%$, A- 49, D- 12\%, D 12\%, D+ 2\%. GRADE C

4.10 Increased sensitivity to duodenal luminal content is a pathophysiological mechanism in functional dyspepsia.
STATEMENT NOT ENDORSED, overall agreement 68\%: $\mathrm{A}+$ $17 \%$, A $51 \%$, A- 29\%, D- 0\%, D 0\%, D+ $2 \%$. GRADE C

4.11 Altered duodenal microbiota composition is a pathophysiological mechanism in functional dyspepsia.

STATEMENT NOT ENDORSED, overall agreement 34\%: A+ $10 \%$, A $24 \%$, A- 39\%, D- 12\%, D 15\%, D+ 0\%. GRADE C

4.12 Impaired vagus nerve function is a pathophysiological mechanism in functional dyspepsia.

STATEMENT NOT ENDORSED, overall agreement 46\%: A+ 15\%, A 31\%, A- 37\%, D- 5\%, D 10\%, D+ 2\%. GRADE C

4.13 Anxiety and stress are pathophysiological mechanisms in functional dyspepsia.

STATEMENT NOT ENDORSED, overall agreement 66\%: A+ $20 \%$, A 46\%, A- 24\%, D- 2\%, D 7\%, D+ 0\%. GRADE B

4.14 Depression is a pathophysiological mechanism in functional dyspepsia.

STATEMENT NOT ENDORSED, overall agreement 54\%: $\mathrm{A}+$ 15\%, A 39\%, A- 24\%, D- 7\%, D 12\%, D+ 2\%. GRADE B

4.15 Disordered central processing of incoming signals from the gastroduodenal region is a pathophysiological mechanism in functional dyspepsia.

STATEMENT ENDORSED, overall agreement 85\%: A+ 39\%, A $46 \%, A-12 \%, D-0 \%$, D $2 \%$, D+ 0\%.

GRADE C

4.16 Genetic factors determine the susceptibility to functional dyspepsia.

STATEMENT NOT ENDORSED, overall agreement 37\%: $\mathrm{A}+$ $22 \%$, A $15 \%, A-42 \%$, D- 5\%, D $15 \%$, D+ $2 \%$. GRADE C

Several studies, both in community-based and in-patient cohorts, have shown that food is a major trigger for FD symptoms. ${ }^{57,73,74}$ Whether alterations in content or timing of meals in FD contributes to this triggering effect has been evaluated in only a few studies. A number of studies reported intake of a lower number of meals in FD patients compared to controls, in some cases with a tendency for more snacks between meals. ${ }^{75-77}$ In terms of macronutrient intake, reduced fat intake has been reported in $\mathrm{FD},{ }^{77}$ but also reduced carbohydrate has been reported in a mixed FD/IBS population. ${ }^{78} \mathrm{~A}$ recent systematic review of 16 studies failed to show a consistent link between symptoms and dietary intake. ${ }^{79}$ Taken together, there are not enough data to confirm that dietary habits induce symptoms in FD patients, but patients are likely to have adapted their food intake patterns in an attempt to decrease symptom occurrence and severity.

In FD patients with otherwise normal macroscopic findings at endoscopy, microscopic $H$. pylori infection has been considered a factor potentially involved in symptom generation. A cause-effect relationship between $H$. pylori infection and FD is supported by evidence that $H$. pylori eradication may lead to sustained symptom improvement in a subset of patients. ${ }^{80}$ The Kyoto consensus proposed that $H$. pylori infection is associated with dyspepsia in a subset of patients, with a strong grade of recommendation and high evidence level, and referred to this entity as $H$. pylori-associated dyspepsia. $^{81}$ The Rome IV consensus has adopted this view. ${ }^{1}$ 
However, there is a possibility of intermittent peptic ulcer disease, missed at endoscopy for dyspeptic symptoms. ${ }^{81,82}$ Furthermore, symptomatic improvement after eradication therapy may also be due to an effect of antibiotics on microbiota other than $H$. pylori infection since $H$. pylori eradication therapy has never been attempted in $H$. pylori-negative FD patients.

Several studies have reported impaired gastric accommodation in $15 \%-50 \%$ of FD patients, ${ }^{63,83-90}$ without differences according to Rome III subgroups. ${ }^{91}$ The impairment of gastric accommodation was associated with reduced drinking capacity and symptoms such as early satiation, fullness, and weight loss. ${ }^{63,67,92}$

Several studies reported delayed gastric emptying in FD for solids as well as liquids ${ }^{93-100}$ without differences in the emptying times between Rome III subgroups. ${ }^{91}$ A meta-analysis described gastric emptying in patients with FD to be 1.46 times slower than in controls. ${ }^{96}$ Delayed gastric emptying was associated with female sex, postprandial fullness, nausea, vomiting, bloating, and early satiety. ${ }^{97-100}$ In spite of the presence of delayed emptying in a subset of patients, the association with symptoms is weak. The severity of gastric emptying delay is not a good determinant of symptom severity or pattern. ${ }^{94,97,99,100}$ Few studies also reported an acceleration of gastric emptying in FD, ${ }^{101,102}$ but this was not confirmed in others. ${ }^{99}$

Hypersensitivity to gastric distention has been reported in $34 \%$ $65 \%$ of FD patients by several studies, ${ }^{64,100-106}$ without difference between Rome III subgroups, ${ }^{91}$ and postprandial sensitivity to gastric distention was even greater than fasting sensitivity. ${ }^{107}$ Hypersensitivity to gastric distention was associated with a higher prevalence of postprandial pain, belching, and weight loss, ${ }^{64}$ and an increase in gastrointestinal symptom severity was observed with increasing visceral sensitivity. ${ }^{108}$

Several studies from around the world have reported increased numbers of activated eosinophils and mast cells in the duodenal mucosa of FD patients. ${ }^{109-115}$ In addition, Ussing chamber experiments demonstrated that this is correlated with impaired duodenal integrity and changes in the expression of cell-to-cell adhesion proteins, as well as functional and structural submucosal neuronal changes. ${ }^{110,112}$ Although the cause-consequence relationship of the barrier defect and immune activation is still unknown, persisting changes in duodenal mucosal immune cells in PI-FD and systemic immune activation in acute compared to unspecified-onset FD suggest the inability of the immune system to handle a triggering (infectious) insult in FD. ${ }^{116,117}$

Although gastric acid secretion is reported as normal, ${ }^{118} \mathrm{FD}$ patients displayed increased spontaneous duodenal acid exposure during the daytime and the late postprandial phase with higher symptom severity in patients with high duodenal acid exposure. ${ }^{119}$ However, the correlation between acid exposure and symptom severity was weak, and the increased duodenal acid exposure could be, at least in part, attributable to delayed duodenal acid clearance as FD patients display decreased duodenal motor activity in response to acid perfusion. ${ }^{119,120}$
A number of studies suggest the implication of gut hormones in the pathophysiology of FD, but the studies are small and findings are heterogeneous. ${ }^{121}$ Early studies focused on cholecystokinin (CCK), as a subset of FD patients had elevated plasma levels, intravenous administration of CCK worsened dyspeptic symptoms, and the selective CCKA antagonist dexloxiglumide reduced symptoms during gastric distention and duodenal lipid infusion. ${ }^{122-124}$ In PDS, ghrelin plasma levels were reported to be reduced. ${ }^{125,126}$ Further studies are needed to elucidate the potential implication of other gut hormones including gastrin, somatostatin, glucagon-like peptide-1, and peptide YY in FD symptom generation. ${ }^{121}$

Duodenal hypersensitivity to luminal acid and lipids has been reported in FD, ${ }^{127,128}$ with induction of nausea and decreased duodenal motor responses in response to acid infusion. ${ }^{129}$ These alterations were found to be chemospecific as they did not occur during saline or dextrose infusion. ${ }^{130}$ However, the number of studies and the sample size are generally low in the available studies.

Data on the duodenal mucosa-associated microbiome in FD are limited to one pilot study involving nine patients, with an increase in Streptococcus and a decrease in the anaerobic genera Prevotella, Veillonella, and Actinomyces compared to healthy controls. ${ }^{131}$ Interestingly, the total mucosal bacterial load correlated with mealrelated symptom severity and quality of life, indicating the potential of targeting the duodenal microbiome in FD. ${ }^{131}$ Studies on the gastric microbiome in FD have shown a significant inverse correlation between the abundance of Prevotella in the gastric fluid and the severity of PDS. ${ }^{132}$

Mucosal vagal sensory nerve endings are involved in the initiation of satiety, nausea, and vomiting by chemical and osmotic stimuli. The vagus nerve is also a major contributor to control upper gastrointestinal motility. ${ }^{133}$ An early study in seven FD patients, using an insulin hypoglycemia test and plasma levels of pancreatic polypeptide, suggested a disturbed efferent vagal function. ${ }^{134}$ The gastric response to sham feeding, a marker for vagal activity, was lower in PDS compared to controls. ${ }^{135}$ Conversely, sham feeding was reported to improve the suppressed response to a liquid nutrient meal in FD. ${ }^{136}$ Slow deep breathing, which is thought to activate the vagus nerve, was associated with improvement of nutrient volume tolerance and quality of life in FD. ${ }^{137}$ Using spectral analysis of cardiac R-R intervals to evaluate vagal tone, Guo et al. showed a decreased vagal tone that was associated with delayed gastric emptying. ${ }^{138}$ Taken together, a number of observations suggest decreased vagal activity in FD, but the studies all occurred in laboratory settings in small groups of patients.

As mentioned above, there is an association of anxiety with FD, and anxiety may precede FD. Moreover, FD is associated with altered brain processing of gastrointestinal (GI) stimuli, altered central nervous system connectivity, and structure and altered expression of neurotransmitter pathways. ${ }^{139-143}$ However, a causal relation between anxiety and FD has not been established. As mentioned above, depression is also associated with FD, but also in this case, there is a lack of evidence for a causal relation. 
Numerous studies have shown that FD patients report more symptoms or earlier symptoms following gastroduodenal stimulation with either balloon, liquid volume, or food compared to healthy controls. A systematic review evaluated studies on central processing of signals from the gastroduodenal region in FD patients and controls, mostly by balloon distention of the stomach, using PET or fMRI technology. ${ }^{144}$ The results show that FD is associated with functional abnormalities in sensory and pain modulation, emotion, saliency, and homeostatic processing regions, suggesting that disordered central processing of incoming signals from the gastroduodenal region is indeed a relevant pathophysiological mechanism at least in a subgroup of FD patients. However, this does not exclude an involvement of peripheral mechanisms as well.

Family studies support a genetic component in FD susceptibility. ${ }^{145}$ A mea-analysis of eight studies indicated that the GNB3 C825T polymorphism is significantly associated with FD, and susceptible to racial variation. ${ }^{146}$ However, a meta-analysis based on 12 studies has failed to confirm a significant association. ${ }^{147}$ Several additional gene polymorphisms including serotonin transporter promoter, interleukin-17F, migration inhibitory factor, cholecystokinin-1 intron 1, cyclooxygenase-1, catechol-o-methyltransferase, transient receptor potential vanilloid 1 receptor, regulated upon activation normal $\mathrm{T}$ cell expressed and secreted, p22PHOX, Toll-like receptor 2, SCN10A, CD14, adrenoreceptors, and others have been investigated in relation to FD; however, the results are contradictory. ${ }^{148}$

\section{Diagnosis}

5.1 Upper gastrointestinal endoscopy is mandatory for establishing a diagnosis of functional dyspepsia. STATEMENT ENDORSED, overall agreement $80 \%$ : A+ 51\%, A $29 \%, A-15 \%, D-0 \%, D 2 \%, D+2 \%$. GRADE A

5.2 In primary care, uninvestigated dyspepsia can be managed without endoscopy if there are no alarm symptoms or risk factors.

STATEMENT ENDORSED, overall agreement 93\%: A+ 32\%, A $61 \%, A-5 \%$, D- 0\%, D 2\%, D+ 0\%.

GRADE A

5.3 Upper gastrointestinal endoscopy is mandatory if there are alarm symptoms or risk factors.

STATEMENT ENDORSED, overall agreement 93\%: A+ 73\%, A $20 \%, A-5 \%$, D- 0\%, D $2 \%$, D+ 0\%.

GRADE A

5.4 Screening blood tests are useful when considering a diagnosis of functional dyspepsia.

STATEMENT NOT ENDORSED, overall agreement 46\%: A+ $10 \%, A 36 \%, A-24 \%$, D- 2\%, D 24\%, D+ $2 \%$. GRADE B

5.5 Every patient with dyspeptic symptoms should be tested for Helicobacter pylori (non-invasively or at gastroscopy). STATEMENT ENDORSED, overall agreement 81\%: A+ 39\%, A $42 \%, A-12 \%, D-0 \%, D$ 7\%, D+ 0\%.

GRADE A

5.6 Patients with dyspepsia and $H$. pylori-positive gastritis should be considered to have functional dyspepsia just if symptoms persist 6 to 12 months after H. pylori eradication.
STATEMENT ENDORSED, overall agreement 83\%: A+ 34\%, A $49 \%, A-12 \%$, D- 0\%, D $2 \%, D+2 \%$.

GRADE B

5.7 Patients with dyspepsia and $H$. pylori-negative gastritis should be considered to have functional dyspepsia.

STATEMENT ENDORSED, overall agreement 85\%: A+ 34\%, A 51\%, A- 10\%, D- 5\%, D 0\%, D+ 0\%. GRADE B

5.8 Functional dyspepsia should be subdivided into EPS and PDS for further diagnostic and therapeutic approach.

STATEMENT ENDORSED, overall agreement 83\%: A+ 34\%, A 49\%, A- 15\%, D- 0\%, D 2\%, D+ 0\%.

GRADE B

5.9 Upper abdominal ultrasound is useful when considering a diagnosis of functional dyspepsia.

STATEMENT NOT ENDORSED, overall agreement 27\%: A+ 12\%, A 15\%, A- 24\%, D- 10\%, D 32\%, D+ 7\%. GRADE B

5.10 A gastric emptying test is useful when considering a diagnosis of functional dyspepsia.

STATEMENT NOT ENDORSED, overall agreement 34\%: A+ $2 \%$, A $32 \%, A-27 \%$, D- 20\%, D 15\%, D+ 5\%. GRADE B

5.11 Esophageal $\mathrm{pH}$ monitoring is useful in functional dyspepsia to rule out GERD.

STATEMENT NOT ENDORSED, overall agreement 37\%: A+ 7\%, A 30\%, A- 29\%, D- 7\%, D 24\%, D+ 2\%. GRADE B

5.12 Increased duodenal eosinophil count is a marker of functional dyspepsia.

STATEMENT NOT ENDORSED, overall agreement 20\%: A+ $3 \%$, A $17 \%$, A- 37\%, D- 15\%, D 27\%, D+ 2\%. GRADE C

5.13 Impaired nutrient volume tolerance is a marker of functional dyspepsia.

STATEMENT NOT ENDORSED, overall agreement 63\%: A+ $14 \%$, A $49 \%, A-22 \%, D-5 \%, D 7 \%, D+2 \%$.

GRADE B

A distinction should be made between the management of uninvestigated dyspeptic symptoms and the diagnosis of FD. The Rome IV definition of FD implies that potential underlying organic disorders have been ruled out by endoscopy. ${ }^{1}$ In a patient presenting with dyspeptic symptoms, all guidelines recommend a prompt upper $\mathrm{Gl}$ endoscopy in patients aged over 45-60 years to rule out neoplasia, and to take biopsies to establish $\mathrm{H}$. pylori status. ${ }^{1,10,149,150}$ Endoscopy is also mandatory in younger patients presenting with alarm features, ${ }^{1,10}$ although alarm symptoms have a limited value in predicting an organic disease. ${ }^{5,151}$ In younger patients without alarming symptoms, guidelines agree that there is no need to perform a gastroscopy to detect malignancy, which is rare. Empiric therapy, either with proton pump inhibitors (PPIs), prokinetics or $\mathrm{H}$. pylori eradication ("test and treat strategy"), is valuable for the management of uninvestigated dyspepsia. When considering the actual diagnosis of FD, endoscopy is mandatory to rule out not only malignancies, but also benign organic disorders which may explain the symptoms such as peptic ulcer (prevalence 8\%), esophagitis (20\%), or $\mathrm{H}$. pylori-associated gastritis. ${ }^{6}$ The cutoff between young and old is now considered to be 60 years in the West, adjusted to additional risk factors and local incidence age of gastric cancer. ${ }^{150}$ 
Overall, there is a lack of data on cost-benefit utility of laboratory testing in patients presenting with dyspeptic symptoms. A study from India found that apart from warning signs, blood tests for hemoglobin and albumin could discriminate functional from organic disease when placed in a risk model, ${ }^{152}$ but the results have not been replicated in Western populations.

Most Western guidelines advocate testing for $H$. pylori in dyspeptic subjects and eradication in case of a positive test. In younger patients $(<60)$, the most cost-effective way to manage dyspeptic patients is to reduce or stop NSAID medication and/or to have a non-invasive test for $H$. pylori. ${ }^{153,154}$ Especially in high prevalence areas, the positive subjects should be considered for follow-up surveillance of early gastric cancer. ${ }^{81}$ If an endoscopy is performed, biopsies should be obtained to test for $H$. pylori status. ${ }^{1,10,81,149,150}$

H. pylori eradication may improve symptoms in a subset of patients with investigated dyspepsia, that is, with normal macroscopic upper $\mathrm{Gl}$ endoscopy, but studies suggest that the symptomatic benefit is only reached after 6-12 months. ${ }^{1,81}$ This subgroup of patients, referred to as $\mathrm{H}$. Pylori-associated dyspepsia, is relatively small, since meta-analysis of randomized controlled trials has shown a $10 \%$ relative risk reduction of persisting symptoms in the $\mathrm{H}$. Pylori eradication group compared to placebo, with a number needed to treat (NNT) of 12.5 to cure one case of dyspepsia. ${ }^{150}$

Although chronic superficial gastritis might affect a variety of gastric functions, there is no evidence to consider that the presence of gastric mucosal inflammation (with or without atrophy) may cause symptoms. ${ }^{1,81,155}$ Therefore, if no $H$. Pylori infection can be demonstrated, a patient with dyspeptic symptoms and normal endoscopy should be considered to have FD even if gastritis is present, whatever its severity. ${ }^{1}$

In population-based symptom analyses, dyspeptic symptoms were shown to group around clusters, representing EPS and PDS. ${ }^{3,156}$ The literature is divided on the usefulness of distinguishing PDS and EPS for patient management. When the Rome III subdivision is used, a major overlap is found between both, which is largely corrected with the Rome IV subdivision as a good separation between both subtypes is now found both in epidemiological studies and in clinical practice. ${ }^{3,11,40,156-158}$ While some studies report different treatment responses, ${ }^{159,160}$ others do not. ${ }^{161,162}$ To date, no fully published study has evaluated differential pathophysiological mechanisms or treatment outcomes according to the Rome IV subdivision. ${ }^{163,164}$

Kraag et al. performed a meta-analysis of 21 controlled studies on the association between gallstones and dyspeptic symptoms and found no reasonable association between gallstones and "classical" dyspeptic symptoms other than upper abdominal pain. ${ }^{165}$ In a systematic review of 24 publications, biliary colic was the only single symptom associated with gallstones. ${ }^{166}$ Hence, guidelines do not recommend upper abdominal ultrasound for exclusion of biliary pathology in the diagnosis of FD. ${ }^{1,150}$

The prevalence of delayed gastric emptying in FD ranges between $20 \%$ and $50 \%$, but its association with symptoms and response to therapy has shown inconsistent results. ${ }^{1,91,167,168}$ The American College of Gastroenterology and Canadian Association of
Gastroenterology, as well as the Rome IV consensus did not recommend the use of gastric emptying testing in the diagnosis or management of FD. ${ }^{1,150}$

Abnormal esophageal acid exposure on $\mathrm{pH}$ monitoring can be found in $20 \%-30 \%$ of patients presenting with dyspeptic symptoms without heartburn as a predominant symptom, and in up to $50 \%$ in the subgroup of patients with epigastric burning. ${ }^{13,169-171}$ Randomized placebo-controlled studies have shown a small but significant benefit of acid-suppressive therapies. ${ }^{1,150}$ However, there is no evidence that esophageal $\mathrm{pH}$ monitoring would help to identify patients who may respond to acid-suppressive therapy. In addition, there is no evidence that $\mathrm{pH}$ monitoring would be useful in patients with dyspeptic symptoms refractory to acid-suppressive therapy.

In a systematic review and meta-analysis of 37 studies, both mast cell and eosinophil counts in the duodenum were increased in FD compared to controls, both in PDS and EPS. ${ }^{172}$ Nevertheless, as there is overlap with health and as other conditions may also be associated with increased eosinophil numbers, this cannot be used as a diagnostic marker.

Several studies have reported decreased volume tolerance in FD compared to health, using liquid nutrients but also water intake. ${ }^{63,67,86,173-175}$ A large drinking test study in secondary care FD patients confirmed decreased nutrient volume tolerance, and this is reproducible and correlates with symptom pattern and severity. ${ }^{176}$ However, the use of different substances (water vs. nutrients) and different rates of ingestion and levels of blinding to the ingested nutrient volume have hampered the development of a standardized protocol that can be useful in the clinical setting.

\section{Treatment}

6.1 Dietary adjustment improves symptoms in FD. STATEMENT NOT ENDORSED, overall agreement 73\%: A+ $22 \%$, A 51\%, A- 24\%, D- 2\%, D 0\%, D+ 0\%. GRADE C

$6.2 \mathrm{H}$. pylori positive FD patients should receive eradication therapy.

STATEMENT ENDORSED, overall agreement 95\%: A+ 59\%, A 36\%, A- 5\%, D- 0\%, D 0\%, D+ 0\%.

GRADE A

6.3 PPI therapy is the most appropriate initial therapy for FD. STATEMENT NOT ENDORSED, overall agreement 73\%: A+ $27 \%$, A $46 \%$, A- 12\%, D- 2\%, D 12\%, D+ 0\%.

GRADE B

6.4 PPI therapy is an effective therapy for FD.

STATEMENT ENDORSED, overall agreement 83\%: A+ 25\%, A $58 \%, A-15 \%, D-2 \%, D$, D + 0\%.

GRADE A

6.5 PPI therapy is the most effective therapy for EPS.

STATEMENT NOT ENDORSED, overall agreement 59\%: A+ $20 \%$, A 39\%, A- 22\%, D- 2\%, D 17\%, D+ 0\%. GRADE C

6.6 Prokinetic therapy is the most appropriate initial therapy for FD.

STATEMENT NOT ENDORSED, overall agreement 30\%: A+ 18\%, A $12 \%$, A- 15\%, D- 12\%, D 38\%, D+ 5\%. GRADE C

6.7 Prokinetic therapy is an effective therapy for FD.

STATEMENT NOT ENDORSED, overall agreement 54\%: A+ $17 \%$, A 37\%, A- 34\%, D- 5\%, D 7\%, D+ 0\%.

GRADE B 
6.8 Prokinetic therapy is the most effective therapy for PDS. STATEMENT NOT ENDORSED, overall agreement 54\%: A+ $22 \%$, A $32 \%$, A- 22\%, D- 5\%, D $17 \%$, D+ $2 \%$. GRADE B

6.9 Efficacy of prokinetics is not related to their enhancement of gastric emptying rate.

STATEMENT NOT ENDORSED, overall agreement 56\%: A+ 7\%, A 49\%, A- 24\%, D- 7\%, D 10\%, D+ 2\%. GRADE B

6.10 Itopride is effective for FD patients.

STATEMENT NOT ENDORSED, overall agreement 56\%: A+ 12\%, A 44\%, A- 30\%, D- 7\%, D 7\%, D+ 0\%. GRADE C

6.11 Tricyclic antidepressants (TCAs) are effective for EPS. STATEMENT NOT ENDORSED, overall agreement 78\%: A+ $20 \%$, A $58 \%$, A- 15\%, D- 0\%, D 5\%, D+ $2 \%$. GRADE B

6.12 TCAs are effective for PDS.

STATEMENT NOT ENDORSED, overall agreement 32\%: A+ $5 \%$, A $27 \%$, A- 24\%, D- $12 \%$, D $27 \%$, D+ 5\%. GRADE B

6.13 TCAs are not effective for PDS.

STATEMENT NOT ENDORSED, overall agreement 39\%: A+ $10 \%$, A $29 \%$, A- 25\%, D- 17\%, D 17\%, D+ 2\%. GRADE B

6.14 Serotonin reuptake inhibitors are effective for FD.

STATEMENT NOT ENDORSED, overall agreement 20\%: $\mathrm{A}+$ $5 \%$, A $15 \%$, A- 17\%, D- 12\%, D 44\%, D+ 7\%. GRADE B

6.15 Serotonin reuptake inhibitors are not effective for FD. STATEMENT NOT ENDORSED, overall agreement 54\%: A+ 7\%, A 47\%, A- 29\%, D- 7\%, D 10\%, D+ 0\%. GRADE B

6.16 Serotonin noradrenaline reuptake inhibitors are effective for FD.

STATEMENT NOT ENDORSED, overall agreement 17\%: A+ 0\%, A 17\%, A- 27\%, D- 12\%, D 39\%, D+ 5\%. GRADE C

6.17 Serotonin noradrenaline reuptake inhibitors are not effective for FD.

STATEMENT NOT ENDORSED, overall agreement 49\%: A+ $5 \%$, A 44\%, A- 24\%, D- 5\%, D 17\%, D+ 5\%. GRADE C

6.18 Mirtazapine is effective for post-prandial distress syndrome patients with weight loss.

STATEMENT NOT ENDORSED, overall agreement 68\%: A+ $12 \%$, A $56 \%$, A- 27\%, D- 0\%, D 5\%, D+ 0\%. GRADE B

6.19 5-HT1A agonists (tandospirone, buspirone, ....) are effective for PDS.

STATEMENT NOT ENDORSED, overall agreement $56 \%$ : A+ $5 \%$, A 51\%, A- 37\%, D- 2\%, D 5\%, D+ 0\%.

GRADE B

6.20 Herbal therapies are effective for FD patients.

STATEMENT NOT ENDORSED, overall agreement 37\%: A+ $12 \%$, A $25 \%$, A- 34\%, D- 10\%, D 17\%, D+ 2\%: . GRADE B

6.21 lberogast (STW-5) is effective for FD patients.

STATEMENT NOT ENDORSED, overall agreement 54\%: A+ $12 \%$, A $42 \%, A-34 \%$, D- 0\%, D 12\%, D+ 0\%. GRADE B

6.22 Rifaximin is effective for FD patients.

STATEMENT NOT ENDORSED, overall agreement 19\%: A+ $2 \%$, A $17 \%, A-27 \%$, D- $10 \%$, D $37 \%$, D+ $7 \%$. GRADE C

6.23 Hypnotherapy is effective for FD patients.

STATEMENT NOT ENDORSED, overall agreement 29\%: A+ $5 \%$, A $24 \%$, A- 22\%, D- 17\%, D 32\%, D+ 0\%. GRADE B
6.24 Cognitive-behavioral therapy (CBT) is effective for FD patients.

STATEMENT NOT ENDORSED, overall agreement 42\%: $\mathrm{A}+$ 10\%, A 32\%, A- 39\%, D- 5\%, D 14\%, D+ 0\%. GRADE B

6.25 Acupuncture is effective for FD patients.

STATEMENT NOT ENDORSED, overall agreement 27\%: A+ 0\%, A $27 \%$, A- 27\%, D- 15\%, D 22\%, D+ 10\%. GRADE B

6.26 Mindfulness is effective for FD patients.

STATEMENT NOT ENDORSED, overall agreement 27\%: A+ $3 \%$, A $24 \%, A-12 \%$, D- 10\%, D 49\%, D+ $2 \%$. GRADE B

6.27 In case of severe weight loss in FD, nutritional support may be needed.

STATEMENT ENDORSED, overall agreement 90\%: A+36\%, A $54 \%, A-7 \%, D-0 \%, D 2 \%, D+0 \%$.

GRADE B

Although the majority of FD patients indicate that their symptoms are triggered by nutrient ingestion, there is a lack of controlled dietary intervention studies. It is reasonable to advise frequent smallsize meals and avoiding high-fat food items, but the supporting evidence for this strategy is rather limited. Large-scale randomized studies are required to evaluate the impact of dietary factors on symptoms of FD and the role of diet as a therapeutic strategy.

A review of 22 trials involving $4896 \mathrm{H}$. pylori-positive FD patients showed that $H$. pylori eradication determined a small but statistically significant improvement of symptoms when compared with placebo ( $\mathrm{RR}$ dyspepsia remaining $=0.91 ; 95 \% \mathrm{Cl}=0.88-0.94 ; p<0.00001$ ). The observation period in most of the trials included in the review was 12 months, and the NNT was $12.5 .{ }^{150}$ Although the overall therapeutic effect is modest, additional benefits of eradication therapy are the elimination of a putative pathogenic factor with prevention of peptic ulcer and possibly gastric cancer. ${ }^{1,81}$ Pre-Rome IV evidence suggests that eradication of $H$. pylori infection could be beneficial in both predominant epigastric pain and predominant dysmotility-type symptoms, although a more recent study showed the main benefit in EPS. ${ }^{160,177}$

Several guidelines recommend standard, once-daily PPI therapy during 4-8 weeks as the first-line treatment for patients with FD who remain symptomatic after eradication of $H$. pylori or who are negative for $H$. pylori. ${ }^{150,178-180}$ A recent Cochrane meta-analysis, including 6172 patients from 18 randomized controlled trials, confirmed that PPIs are more effective than placebo in the reduction of global symptoms of FD (RR of remaining dyspeptic $0.88 ; 95 \% \mathrm{Cl}$ 0.82-0.94; NNT 11). ${ }^{181}$ There were no differences between low- and high-dose PPI, type of PPI, and H. pylori status. ${ }^{150,181,182}$ In a metaanalysis of two studies including 740 FD patients, directly comparing PPI and histamine-2 receptor antagonists, there was no difference between both treatments. ${ }^{181}$ However, both studies are older, possibly including GERD patients, and one is only available in abstract form. ${ }^{183,184}$ In areas of low (<20\%) prevalence of H. pylori, a course of PPI has been suggested as the preferred first-line option before a test-and-treat approach. ${ }^{185}$ The Rome IV consensus stated that PPIs are ineffective in relieving PDS symptoms, based on older data. ${ }^{1}$ Two Japanese studies that investigated the effect of PPI in the 
Rome III/IV subgroups found no significant difference between subgroups. ${ }^{177,186}$ The ACG/CAG guidelines, based on an updated metaanalysis, propose PPI as first-line therapy, irrespective of the Rome IV subgroups. ${ }^{150}$

A recent meta-analysis of 29 studies involving 10,044 patients with FD demonstrated a significant effect of prokinetics in reducing dyspeptic symptoms (RR of ongoing dyspeptic symptoms 0.81; 95\% $\mathrm{Cl}$ [0.74-.89]) with an NNT of $7 .{ }^{187}$ However, the studies showed significant heterogeneity and the funnel plot was asymmetrical, suggesting publication bias. Moreover, 12 studies involved cisapride, which has been withdrawn from the market because of cardiac adverse events. ${ }^{188}$ When cisapride was removed from the metaanalysis, the overall effect was still significant, but the NNT increased to $12 .{ }^{187}$

The rationale for prokinetic therapy in FD is the presence of motor abnormalities such as delayed gastric emptying, especially in PDS, but in a large study, similar prevalence of gastric motor abnormalities was found in PDS, EPS, and the overlap group. ${ }^{91}$ In the 2019 meta-analysis, prokinetics demonstrated similar efficacy in PDS and EPS subgroups, although only two studies included a total of 124 EPS patients, ${ }^{187}$ one of which is a study on cisapride from $1989 .{ }^{189}$ The evidence supporting the use of prokinetics in FD is rather poor and no target subgroup can be defined based on the available evidence. Moreover, many prokinetics such as domperidone and acotiamide, are not widely available. Adverse effects, such as extrapyramidal syndrome for many dopamine-2 (D2) receptor antagonists and QTc prolongation with domperidone, are limiting chronic use in FD. This has led the ACG/CAG guideline to recommend treatment with a TCA in patients refractory to PPI treatment before prokinetics. ${ }^{150}$

A systematic analysis of 34 studies failed to demonstrate a correlation between the acceleration of gastric emptying and symptom improvement. ${ }^{167}$ One possible explanation is the heterogeneous pathophysiology of FD, involving not only delayed gastric emptying but also impaired gastric accommodation and hypersensitivity to gastric distention which are often not taken into account. However, in a recent meta-analysis by Vijayvargiya et al., the authors found that when optimal test methods were used, a selection of promotility agents significantly accelerated gastric emptying and produced significant symptom improvement in gastroparesis patients. ${ }^{168}$ Nevertheless, it has not been established that the effect of prokinetics in FD depends on baseline emptying rate or improvement of emptying rate with therapy.

Itopride is a combined D2 antagonist and acetylcholinesterase inhibitor and is available in Asia and several countries in Eastern Europe. A phase IIb placebo-controlled trial found significantly more responders to itopride, based on a global efficacy measure. ${ }^{190}$ However, no significant improvement over placebo in reduction of FD symptoms was observed in two subsequent Phase III trials. ${ }^{191}$ These trials suffered from issues with patients and endpoint selection, ${ }^{192}$ but their negative outcome stopped further development of itopride in the West. In a recent controlled trial in Belgium, itopride seemed more effective in Rome IV PDS compared to Rome III PDS. ${ }^{193}$
Psychotropic drugs appear to be an effective treatment for FD, as demonstrated by a systematic review and meta-analysis, with an NNT of 6 when data from all studies were pooled (1241 patients, 673 assigned to psychoactive drugs, and 568 to placebo). However, this beneficial effect appeared to be limited to TCAs and antipsychotics. ${ }^{194}$ In a randomized placebo-controlled trial including 292 FD patients assigned to either placebo, $50 \mathrm{mg}$ amitriptyline or $10 \mathrm{mg}$ escitalopram for 12 weeks, subjects with "ulcer-like" FD (likely equivalent to EPS) receiving amitriptyline reported more adequate relief of symptoms than those receiving placebo or escitalopram $(p=0.06) .{ }^{195}$ There were adverse events in $30 \%(n=29)$ individuals in the amitriptyline arm, leading to discontinuation of treatment in two of them. Those with delayed gastric emptying were less likely to report adequate relief on amitriptyline compared with FD patients with normal emptying, but this was not related to an amitriptyline-induced delay in gastric emptying. ${ }^{194}$ Amitriptyline appeared to derive its benefit predominantly through improving abdominal pain, since no change in psychological distress measures nor gastric emptying rates was found. ${ }^{195,196}$ In the subset of patients with PDS, little evidence exists so far supporting the use of TCA's. A double-blind, randomized controlled trial including 107 patients with refractory $F D$, treated with either imipramine or placebo for 12 weeks, showed efficacy in symptom relief ( $p=0.0051$ ), but $18 \%$ of the patients on imipramine discontinued the study due to adverse effects. In this study, no conclusion was made regarding efficacy in FD subtypes. ${ }^{197}$ The ACG and CAG clinical guidelines on dyspepsia considered that FD patients failing to respond to PPI and $H$. pylori eradication treatment, should be offered TCA before prokinetics based on the superior evidence for TCA in this indication. No consideration was done based on FD subtypes EPS and PDS. ${ }^{150}$

The systematic review and meta-analysis on the efficacy of psychotropics in FD included two studies of selective serotonin reuptake inhibitors (sertraline $50 \mathrm{mg}$ o.d. and escitalopram $10 \mathrm{mg}$ o. d.), containing almost 400 patients, which were negative. ${ }^{194,195,198}$ Thus, it seems reasonable to assume that these drugs are of no benefit in FD.

A double-blind clinical trial randomly assigned 160 FD patients to 8 weeks of treatment with venlafaxine or placebo. ${ }^{199}$ At none of the measurement times there was a statistically significant difference in symptom severity, quality of life or anxiety, and depression scores between venlafaxine and placebo. ${ }^{199}$ The dropout rate among venlafaxine-treated patients was high due to side effects. While this single study with venlafaxine in FD was negative, it remains to be elucidated whether certain groups of patients might benefit from treatment with serotonin/noradrenaline reuptake inhibitors with a more potent analgesic effect at lower doses, for example, duloxetine.

In FD, weight loss is normally considered an alarming symptom, but may be present in up to $40 \%$ of tertiary care FD patients. ${ }^{10,65,66} \mathrm{~A}$ controlled trial to assess mirtazapine's efficacy in FD and weight loss randomly assigned 34 patients to placebo or mirtazapine $15 \mathrm{mg}$ daily for 8 weeks. $^{200}$ Mirtazapine significantly improved early satiation scores and nutrient tolerance compared to placebo. A trend was 
found for overall dyspepsia symptom score at week 4 in the mirtazapine group, but not at week 8 . Nevertheless, this was associated with significant recovery of weight loss, improvement of quality of life, and visceral specific anxiety score. Another trial treated 60 FD patients with depression and weight loss with either mirtazapine $30 \mathrm{mg}$ daily, paroxetine $20 \mathrm{mg}$ daily or conventional therapy, and showed that mirtazapine did not only alleviate symptoms associated with dyspepsia and depression linked to FD with weight loss, but also significantly increased body weight. ${ }^{201}$ In summary, two limited size trials showed the efficacy of mirtazapine in FD, one in patients without and one in patients with coexisting depression.

Tandospirone citrate, a serotonin $1 \mathrm{~A}$ receptor (5-HT1A) agonist, was shown to improve abdominal symptom scores in FD patients. ${ }^{200}$ However, R-137696, another 5-HT1A agonist, failed to improve symptoms or visceral hypersensitivity in FD patients. ${ }^{203}$ In a small cross-over controlled trial, buspirone significantly reduced the overall severity of symptoms of dyspepsia and individual symptoms of postprandial fullness, early satiation, and upper abdominal bloating, whereas placebo had no significant effect. $^{204}$ The presumed mechanism of action was an enhancement of gastric accommodation. ${ }^{205}$ A meta-analysis of the three available studies with 5-HT1A agonists in FD showed no overall beneficial effect. ${ }^{194}$

Meta-analyses pooling data from different small clinical trials that fall under the FD category indicate that the European herbal combination drug STW-5 and peppermint oil are superior compared to placebo in the treatment of FD symptoms. ${ }^{192,206,207}$ A metaanalysis of five controlled trials found superiority over placebo of an encapsulated peppermint/caraway oil preparation in FD for overall symptoms and epigastric pain and discomfort. ${ }^{208}$

A meta-analysis including 24 clinical trials evaluated the efficacy of the Japanese herbal KAMPO preparation Rikkunshito in FD. ${ }^{209}$ No significant benefit was found when evaluating upper gastrointestinal symptoms based on the Gastrointestinal Symptom Rating Scale, but Rikkunshito was superior to placebo in improving symptoms based on a five-point scale and in improving appetite, although the authors identified risk of bias for the majority of available studies.

Meta-analyses of numerous controlled trials of low quality and small numbers of participants show that different Chinese Herbal Medicines, alone or in combination with variable prokinetic medications, may be effective and superior to prokinetic medication alone when evaluated with variable FD symptom scores. Effects of Chinese Herbal Medicines on individual FD symptoms are largely unreported. $^{210}$

A single double-blind, placebo-controlled randomized study examined the efficacy of rifaximin in subjects with Rome III criteria defined FD who were $H$. pylori negative. ${ }^{211}$ The authors found that rifaximin was superior to placebo for the relief of global dyspeptic symptoms, postprandial fullness/bloating, and belching. Additional future trials are needed to examine the efficacy of rifaximin in FD and to elucidate the underlying mechanism of action.

In a 2017 review, a total of 12 controlled trials of psychological therapies involving 1563 FD patients were identified. ${ }^{150}$ All trials reported a statistically significant benefit of psychological therapies over control, which was most commonly usual management. Information on individual types of psychological therapies is variable. For hypnotherapy in FD, only one small randomized controlled study reported benefit. ${ }^{212}$ For CBT, two studies showed positive shortterm effects on FD symptoms. ${ }^{213,214}$

Meta-analyses of numerous low-quality randomized, controlled studies suggest manual and electric acupuncture being effective in the treatment of FD, as shown by improved symptom scores and health-related quality-of-life scores. ${ }^{215-217}$ Effects are most pronounced in sham-controlled trials and less pronounced in trials comparing to prokinetic medication or traditional Chinese medicine. A recent sham-controlled trial adds that the effect of acupuncture, following 20 treatment sessions in a 4-week episode, is sustained for 24 weeks. ${ }^{218}$ Besides the overall small number of patients included and the different acupuncture protocols followed, selection bias, performing bias, reporting bias, attrition bias, and blinding difficulties remain the major concerns when interpreting findings in the metaanalyses.

In a meta-analysis, the quality and effectiveness of mindfulnessbased therapy in FGIDs was evaluated. ${ }^{219}$ However, studies evaluating the effectiveness of mindfulness specifically in FD have not been found in the literature.

While severe weight loss may occur in FD patients, especially in those with PDS and food avoidance, few studies have addressed its management. The antidepressant mirtazapine seems to help with weight gain in these patients ${ }^{200,201}$ and to improve FD symptoms, so the conclusion that other clinical management strategies for weight-gain support may also be effective, is plausible but has not been tested. This holds true specifically for enteral and parenteral feeding. In one preliminary report of 19 FD patients with delayed gastric emptying and severe weight loss $(15.8 \pm 2.8 \mathrm{~kg})$, enteral feeding through a percutaneous endoscopic gastrojejunostomy $(P E G / J)$ generated weight gain in $63 \%$ of subjects, but there were many non-life-threatening complications. The PEG/J was electively removed after $19.9 \pm 5.6$ months and a mean weight gain of $6.1 \pm 0.8 \mathrm{~kg}^{220}$

\section{Prognosis of FD}

7.1 The long-term prognosis is favorable in the majority of patients with FD.

STATEMENT ENDORSED, overall agreement 85\%: A+ 29\%, A $56 \%, A-12 \%, D-0 \%, D 2 \%, D+0 \%$.

GRADE B

7.2 Life expectancy in FD is similar to the general population. STATEMENT ENDORSED, overall agreement 100\%: A+ 56\%, A 44\%, A- 0\%, D- 0\%, D 0\%, D+ 0\%.

GRADE A

It is well established that symptoms in FD vary over time. Based on a cohort study, 1 year after initial diagnosis, $24 \%$ of patients reported their symptoms as unimproved, and these patients were younger and had higher symptom severity at the first diagnosis. ${ }^{219}$ In a tertiary care cohort, half of the FD patients improved or became asymptomatic after a mean follow-up of 
TABLE 4 Summary of the ESNM consensus on FD

\section{Recommendations}

Dyspepsia refers to a symptom or set of symptoms that are considered to originate from the gastroduodenal region. Early satiation, postprandial fullness, epigastric pain and epigastric burning are the cardinal dyspeptic symptoms.

FD is a condition characterized by chronic dyspeptic symptoms in the absence of organic, systemic or metabolic condition (s) that is (are) likely to explain symptoms. The vast majority of patients with dyspeptic symptoms and no alarm symptoms in the general population would be identified as FD after investigation (if performed).

Two main subtypes of FD are distinguished which may overlap: postprandial distress syndrome (PDS) characterized by meal-induced symptoms (early satiation, postprandial fullness) and epigastric pain syndrome (EPS), with epigastric pain and/or epigastric burning.

Dyspeptic symptoms often co-exist with other symptoms such as bloating in the upper abdomen, nausea and belching. Typical reflux symptoms and irritable bowel syndrome often coexists with FD.

(Functional) dyspepsia is more prevalent in women than men.

Acute GI infection and anxiety are risk factors for development of FD.

FD is a major source of healthcare costs, self-costs to patients and loss of work productivity.

FD is associated with a significant decrease in quality of life and with psychosocial co-morbidities.

Weight loss can be consequence of FD.

Healthcare consulting behavior in FD is driven by symptom severity and impact, and by psychosocial co-morbidities.

$H$. pylori is a cause of symptoms in a subgroup of patients with dyspepsia and normal endoscopy.

Impaired gastric accommodation, delayed gastric emptying, hypersensitivity to gastric distention and disordered central processing of incoming signals from the gastroduodenal region are pathophysiological mechanisms in FD

Upper GI endoscopy is mandatory for establishing a diagnosis of FD, but in primary care, dyspepsia can be managed without endoscopy if there are no alarm of risk factors. The endoscopy is mandatory if there are alarm symptoms or risk factors

Every patient with dyspeptic symptoms should be tested for $H$. pylori ( $\mathrm{Hp}$ ) (non-invasively or at gastroscopy). $H$. pylori positive FD patients should receive eradication therapy. Patients with dyspepsia and $H$. pylori positive gastritis should be considered to have FD if symptoms persist 6 to 12 months after $H$. pylori eradication. Patients with dyspepsia and $H$. pylori negative gastritis should be considered to have FD.

FD should be subdivided into EPS and PDS for further diagnostic and therapeutic approach

PPI-therapy is an effective therapy for FD.

In case of severe weight loss in FD, nutritional support may be needed.

The long-term prognosis is favorable in the majority of patients with FD, whose life expectancy is similar to that of the general population.
Based on statement(s)

1.1, 1.2

1.3, 1.4

1.5

$1.6,1.9,1.11$

2.2

2.3; 2.6

$3.1,3.2,3.3$

$3.4,3.5$

3.6

3.8, 3.9

4.2

$4.3,4.4,4.6,4.15$

$5.1,5.2,5.3$

$5.5,5.6,5.7,6.2$

5.8

6.4

6.27

$7.1,7.2$
5 years, with anxiety and weight loss at presentation as unfavorable predictors. ${ }^{48}$ Population-based reports of longer observation periods performed in Olmsted County, Minnesota, United States (12 years) and Iceland (10 years) report a favorable outcome with symptom resolution in $63 \%-67 \%$, stable or persistent symptoms falling under the FD category in 16\%-20\%, and fluctuating or additional symptoms in 32\%-35\% confirming high symptom turnover among FGID patients. ${ }^{222,223}$

In a population-based cohort study, 5262 randomly selected subjects were screened. From 3933 eligible subjects included in the analysis, dyspepsia was diagnosed in $2 \%$ of subjects. No association with overall survival was detected for dyspepsia $(\mathrm{HR}=1.08(95 \% \mathrm{Cl}$ : $0.58-2.02)) .^{224}$ A 10-year long-term follow-up study included 8323 people, of whom dyspepsia was diagnosed in 3169 patients (38.1\%). After multivariate analysis, there was no significant difference in the likelihood of death at 10 years in those with dyspepsia (HR: 0.94; 99\%
Cl: 0.58-1.54) compared to those who did not meet the criteria for FD. ${ }^{225}$ Thus, available data show that life expectancy in FD is similar to life expectancy in the general population.

\section{RECOMMENDATIONS}

Based on the statements that achieved consensus (Table 3), a number of recommendations for understanding and managing FD can be made, which are summarized in Table 4. The Delphi process also identified several areas of uncertainty, which require additional evidence or further research. Figure 1 schematically summarizes the findings.

The Rome IV definition with four cardinal symptoms (early satiation, postprandial fullness, epigastric pain, and epigastric burning), its subdivision into EPS and PDS, and accessory symptoms (upper 


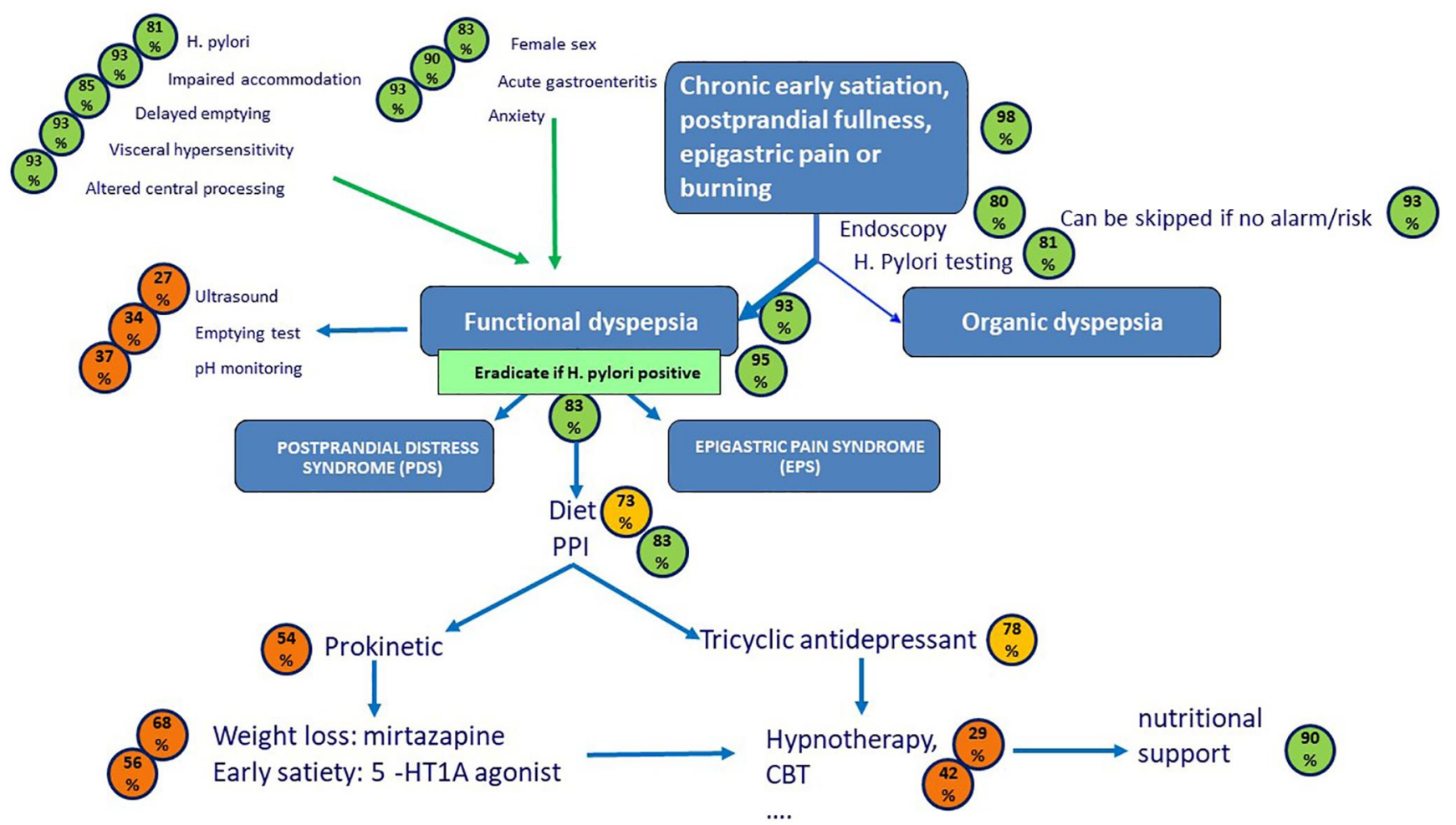

FIG URE 1 Schematic representation, in an algorithm-like fashion, of the outcome of the consensus on functional dyspepsia management. The blue arrows depict the diagnostic and therapeutic flow of the patient. Green arrows refer to risk or pathophysiological factors. The circles depict the $\%$ of agreement, using a green color for $\geq 80 \%$ consensus, light orange for consensus between $70 \%$ and $80 \%$, and dark orange for lower levels of consensus

abdominal bloating, nausea, belching) are well-accepted. There is also consensus that the majority of uninvestigated dyspepsia in the general population represents FD, if an investigation would be done. Overlap with GERD and IBS is acknowledged. Also well accepted are the female predominance of FD, and acute gastrointestinal infections and anxiety as risk factors for developing FD. There is a clear consensus on the impact of FD on the personal level (quality of life, self-cost), on healthcare costs, on the ability to work, and on psychosocial well-being.

In terms of pathophysiological mechanisms that are relevant to FD, consensus supports a role for impaired gastric accommodation, delayed gastric emptying, hypersensitivity to gastric distention, $H$. pylori infection, and altered central processing of incoming signals from the gastroduodenal region. There is no consensus on duodenal mucosal alterations, sensitivity to luminal contents, peptide release, or microbiota. Anxiety is a risk factor for the development of functional dyspepsia; however, anxiety, depression, or stress is not considered a pathophysiological mechanism that underlies FD symptom generation.

There is consensus that endoscopy is mandatory for establishing a firm diagnosis of FD, but that patients in primary care with dyspeptic symptoms and no alarm symptoms or risk factors can be managed without endoscopy. There is consensus that endoscopy is mandatory in case of alarm symptoms or risk factors, and that $\mathrm{H}$. pylori status should be determined at endoscopy or non-invasively in every patient. There is no consensus on the benefit of additional examinations including laboratory testing, abdominal ultrasound, gastric emptying testing, or esophageal $\mathrm{pH}$ monitoring.

The biggest area of lack of consensus is the section on treatment approaches for FD. There is an agreement to use to subdivision in PDS and EPS to guide management, but the vast majority of treatment options are not supported for a specific subgroup. There is consensus to eradicate every $H$. pylori positive FD patient, and PPI therapy is considered an effective therapy for FD, although there is no consensus that it is the preferred initial therapy. There is no consensus on the indication and efficacy of prokinetics or antidepressants, but an almost-agreement (78\%) on the use of TCA in EPS. There is also no consensus on the use of other neuromodulators, herbal therapies, acupuncture, or psychological therapies in FD. There is agreement on the use of nutritional support in case of severe weight loss. Finally, there is consensus that the long-term prognosis of FD is favorable and that life expectancy is not shortened in FD.

The areas of uncertainty revealed by this consensus are multiple. Further unraveling of the FD symptom pattern is useful, and especially the concept of using pictograms deserves additional, preferably multilingual and multicultural studies. These may aid further diagnostic refinement, where the currently only supported tools are endoscopy and $H$. pylori status assessments, with their limited sensitivity and impact on management and outcome. While there is acceptance of a role for gastric sensorimotor dysfunction in 
triggering FD symptoms, the role of duodenal luminal or mucosal alterations is not established, but the $76 \%$ amount of agreement is still considerable. The putative entity of $H$. pylori-associated dyspepsia is poorly described and needs further characterizing studies, especially in the West. The voting on the therapy statements clearly establishes the need for more therapeutic trials, preferably in a multi-center setting using validated endpoints. In the absence of a well-established path to regulatory approval, scientific or professional organizations such as the ESNM or the Rome Foundation may consider taking the lead here.

\section{CONCLUSION}

FD is a highly prevalent and impactful clinical condition. This Delphi process used a multinational and multidisciplinary group of European experts to summarize the current state of consensus on definition, symptom characteristics, pathophysiology, diagnosis, treatment, and prognosis of this condition. The Consensus Group voted on several statements that may guide clinicians in recognizing, diagnosing, and treating FD in clinical practice, whereas the statements without consensus identify areas in need of future research.

\section{ACKNOWLEDGEMENT}

This consensus was supported by a grant from United European Gastroenterology.

\section{AUTHOR CONTRIBUTIONS}

Drafted consensus questions, drafted literature review sections, set up the voting and summaries access, participated in voting, summarized voting outcomes, reviewed and corrected the manuscript: L. Wauters. Drafted consensus questions, drafted literature review sections, participated in voting, reviewed and corrected the manuscript: R. Dickman. Drafted consensus questions, drafted literature review sections, participated in voting, reviewed and corrected the manuscript: V. Drug. Drafted consensus questions, drafted literature review sections, participated in voting, reviewed and corrected the manuscript: A. Mulak. Drafted consensus questions, drafted literature review sections, participated in voting, reviewed and corrected the manuscript: J. Serra. Co-initiated the process, obtained funding, drafted consensus questions, drafted literature review sections, participated in voting, reviewed and corrected manuscript content: P. Enck. Co-initiated the process, drafted consensus questions, drafted literature review sections, wrote manuscript sections, participated in voting, wrote manuscript, reviewed and corrected content: J. Tack. Drafted consensus questions, wrote manuscript sections, participated in voting, reviewed and corrected content: All members of the ESNM FD consensus group (A. Accarino, G. Barbara, S. Bor, B. Coffin, M. Corsetti, H. De Schepper, D. Dumitrascu, A. Farmer, G. Gourcerol, G. Hauser, T. Hausken, G. Karamanolis, D. Kestzhelyi, C. Malagelada, T. Milosavljevic, J. Muris, C. O'Morain, A. Papathanasopoulos, D. Pohl, D. Rumyantseva, G. Sarnelli, E. Savarino, J. Schol, A. Sheptulin, A
Smet, A. Stengel, O. Storonova, M. Storr, H. Törnblom, T. Vanuytsel, M. Velosa, M. Waluga, N. Zarate, F. Zerbib).

\section{ORCID}

Ram Dickman (D) https://orcid.org/0000-0002-6477-2849

Agata Mulak (D) https://orcid.org/0000-0003-4678-8393

Jan Tack (D) https://orcid.org/0000-0002-3206-6704

\section{REFERENCES}

1. Stanghellini V, Talley N, Chan F, Hasler B, Malagelada J, Suzuki H, et al. Functional gastroduodenal disorders. Gastroenterology. 2016;150(6):1380-92.

2. Sperber AD, Bangdiwala SI, Drossman DA, Ghoshal UC, Simren M, Tack J, et al. Worldwide prevalence and burden of functional gastrointestinal disorders, results of Rome foundation global study. Gastroenterology. 2020;S0016-5085:30487. https://doi.org/10. 1053/j.gastro.2020.04.014

3. Tack J, Talley NJ. Functional dyspepsia-symptoms, definitions and validity of the Rome III criteria. Nat Rev Gastroenterol Hepatol. 2013;10:134-41.

4. Ford AC, Marwaha A, Lim A, Moayyedi P. What is the prevalence of clinically significant endoscopic findings in subjects with dyspepsia? Systematic review and meta-analysis. Clin Gastroenterol Hepatol. 2010;8(10):830-7.

5. Vakil N, Moayyedi P, Fennerty MB, Talley NJ. Limited value of alarm features in the diagnosis of upper gastrointestinal malignancy: systematic review and meta-analysis. Gastroenterology. 2006;131(2):390-401.

6. Tack J, Camilleri M. New developments in the treatment of gastroparesis and functional dyspepsia. Curr Opin Pharmacol. 2018:43:111-7.

7. Van den Houte K, Carbone F, Tack J. Postprandial distress syndrome: stratification and management. Expert Rev Gastroenterol Hepatol. 2019;3(4):337-43.

8. Mullen PM. Delphi: myths and reality. J Health Organ Manag. 2003;17:37-52

9. Balshem $\mathrm{H}$, Helfand $\mathrm{M}$, Schunemann $\mathrm{HJ}$, et al. GRADE guidelines: 3. Rating the quality of evidence. J Clin Epidemiol. 2011;64:401-6.

10. Tack J, Talley NJ, Camilleri M, Holtmann G, Hu P, Malagelada JR, et al. Functional gastroduodenal disorders. Gastroenterology. 2006;130(5):1466-79.

11. Van den Houte K, Carbone F, Goelen N, Schol J, Masuy I, Arts J, et al. Effects of Rome IV definitions of functional dyspepsia subgroups in secondary care. Clin Gastroenterol Hepatol. 2020;620: S1542-3565. https://doi.org/10.1016/j.cgh.2020.06.043. Online ahead of print.30906-X

12. Enck P, Azpiroz F, Boeckxstaens G, Elsenbruch S, Feinle-Bisset C, Holtmann G, et al. Functional dyspepsia. Nat Rev Dis Primers. 2017;3:17081.

13. Geeraerts A, Van Houtte B, Clevers E, Geysen H, Vanuytsel T, Tack $J$, et al. Gastroesophageal reflux disease-functional dyspepsia overlap: do birds of a feather flock together? Am J Gastroenterol. 2020;115(8):1167-82.

14. Pleyer C, Bittner H, Locke GR, 3rd, Choung RS, Zinsmeister AR, Schleck CD, et al. Overdiagnosis of gastro-esophageal reflux disease and underdiagnosis of functional dyspepsia in a USA community. Neuro Gastroenterol Motil. 2014;26(8):1163-71.

15. Quigley EM, Lacy BE. Overlap of functional dyspepsia and GERD-diagnostic and treatment implications. Nat Rev Gastroenterol Hepatol. 2013;10(3):175-86 
16. de Bortoli N, Tolone S, Frazzoni M, Martinucci I, Sgherri G, Albano $\mathrm{E}$, et al. Gastroesophageal reflux disease, functional dyspepsia and irritable bowel syndrome: common overlapping gastrointestinal disorders. Ann Gastroenterol. 2018;31(6):639-48.

17. Ford AC, Marwaha A, Lim A, Moayyedi P. Systematic review and metA-analysis of the prevalence of irritable bowel syndrome in individuals with dyspepsia. Clin Gastroenterol Hepatol. 2010;8(5):401-9.

18. Tack J, Carbone F, Holvoet L, Vanheel H, Vanuytsel T, Vandenberghe $A$. The use of pictograms improves symptom evaluation by patients with functional dyspepsia. Aliment Pharmacol Ther. 2014;40(5):523-30.

19. Ford AC, Marwaha A, Sood R, Moayyedi P. Global prevalence of, and risk factors for, uninvestigated dyspepsia: a meta-analysis. Gut. 2015;64(7):1049-57.

20. Tougas G, Chen Y, Hwang P, Liu MM, Eggleston A. Prevalence and impact of upper gastrointestinal symptoms in the Canadian population: findings from the DIGEST study. Domestic/International Gastroenterology Surveillance Study. Am J Gastroenterol. 1999;94(10):2845-54.

21. Li Y, Nie Y, Sha W, Su H. The link between psychosocial factors and functional dyspepsia: an epidemiological study. Chin Med J (Engl). 2002;115(7):1082-4.

22. Hirakawa K, Adachi K, Amano K, Katsube T, Ishihara S, Fukuda R, et al. Prevalence of non-ulcer dyspepsia in the Japanese population. J Gastroenterol Hepatol. 1999;14(11):1083-7.

23. Futagami $\mathrm{S}$, Itoh $\mathrm{T}$, Sakamoto $\mathrm{C}$. Systematic review with metA -analysis: post-infectious functional dyspepsia. Aliment Pharmacol Ther. 2015;41(2):177-88.

24. Porter CK, Faix DJ, Shiau D, Espiritu J, Espinosa BJ, Riddle MS. Postinfectious gastrointestinal disorders following norovirus outbreaks. Clin Infect Dis. 2012;55(7):915-22.

25. Dizdar V, Gilja OH, Hausken T. Increased visceral sensitivity in GiardiA-induced postinfectious irritable bowel syndrome and functional dyspepsia. Effect of the 5HT3-antagonist ondansetron. Neuro Gastroenterol Motil. 2007;19(12):977-82.

26. Ford AC, Thabane M, Collins SM, Moayyedi P, Garg AX, Clark WF, et al. Prevalence of uninvestigated dyspepsia 8 years after a large waterborne outbreak of bacterial dysentery: a cohort study. Gastroenterology. 2010;138(5):1727-36.

27. Tack J, Demedts I, Dehondt G, Caenepeel P, Fischler B, Zandecki $M$, et al. Clinical and pathophysiological characteristics of acute-onset functional dyspepsia. Gastroenterology. 2002;122(7):1738-47.

28. Shaib Y, El-Serag HB. The prevalence and risk factors of functional dyspepsia in a multiethnic population in the United States. Am J Gastroenterol. 2004;99(11):2210-6.

29. Moayyedi P, Forman D, Braunholtz D, Feltbower R, Crocombe W, Liptrott $M$, et al. The proportion of upper gastrointestinal symptoms in the community associated with Helicobacter pylori, lifestyle factors, and nonsteroidal anti-inflammatory drugs. Leeds HELP Study Group. Am J Gastroenterol. 2000;95(6):1448-55.

30. Holtmann G, Gschossmann J, Buenger L, Gerken G, Talley NJ. Do changes in visceral sensory function determine the development of dyspepsia during treatment with aspirin? Gastroenterology. 2002;123(5):1451-8.

31. Mahadeva S, Goh KL. Epidemiology of functional dyspepsia: a global perspective. World J Gastroenterol. 2006;12(17):2661-6.

32. Paula H, Grover M, Halder SL, Locke GR, 3rd, Schleck CD, Zinsmeister AR, et al. Non-enteric infections, antibiotic use, and risk of development of functional gastrointestinal disorders. Neuro Gastroenterol Motil. 2015;27(11):1580-6.

33. Lacy BE, Everhart K, Crowell MD. Functional dyspepsia is associated with sleep disorders. Clin Gastroenterol Hepatol. 2011;9(5):410-4.
34. Quadri A, Vakil N. Health-related anxiety and the effect of openaccess endoscopy in US patients with dyspepsia. Aliment Pharmacol Ther. 2003;17(6):835-40.

35. Mak AD, Wu JC, Chan Y, Chan FK, Sung JJ, Lee S. Dyspepsia is strongly associated with major depression and generalised anxiety disorder - a community study. Aliment Pharmacol Ther. 2012;36(8):800-10.

36. Hu WH, Wong WM, Lam CL, Lam KF, Hui WM, Lai KC, et al. Anxiety but not depression determines health care-seeking behaviour in Chinese patients with dyspepsia and irritable bowel syndrome: a population-based study. Aliment Pharmacol Ther. 2002;16(12):2081-8.

37. Mujakovic S, de Wit NJ, van Marrewijk CJ, Fransen GA, Laheij RJ, Muris JW, et al. Psychopathology is associated with dyspeptic symptom severity in primary care patients with a new episode of dyspepsia. Aliment Pharmacol Ther. 2009;29(5):580-8.

38. Van Oudenhove L, Vandenberghe J, Geeraerts B, Vos R, Persoons $P$, Fischler $B$, et al. Determinants of symptoms in functional dyspepsia: gastric sensorimotor function, psychosocial factors or somatisation? Gut. 2008;57(12):1666-73.

39. Koloski NA, Jones M, Talley NJ. Evidence that independent gut-tobrain and brain-to-gut pathways operate in the irritable bowel syndrome and functional dyspepsia: a 1-year population-based prospective study. Aliment Pharmacol Ther. 2016;44(6):592-600.

40. Aziz I, Palsson OS, Törnblom H, Sperber AD, Whitehead WE, Simrén M. Epidemiology, clinical characteristics, and associations for symptom-based Rome IV functional dyspepsia in adults in the USA, Canada, and the UK: a cross-sectional population-based study. Lancet Gastroenterol Hepatol. 2018;3(4):252-62.

41. Aro P, Talley NJ, Ronkainen J, Storskrubb T, Vieth M, Johansson $\mathrm{SE}$, et al. Anxiety is associated with uninvestigated and functional dyspepsia (Rome III criteria) in a Swedish population-based study. Gastroenterology. 2009;137(1):94-100.

42. Aro P, Talley NJ, Johansson SE, Agréus L, Ronkainen J. Anxiety is linked to new-onset dyspepsia in the Swedish population: a 10year follow-up study. Gastroenterology. 2015;148(5):928-37.

43. Jones MP, Oudenhove LV, Koloski N, Tack J, Talley NJ. Early life factors initiate a 'vicious circle' of affective and gastrointestinal symptoms: a longitudinal study. United European Gastroenterol J. 2013;1(5):394-402.

44. De la RocA-Chiapas JM, Solís-Ortiz S, Fajardo-Araujo M, Sosa M, CórdovA-Fraga T, RosA-Zarate A. Stress profile, coping style, anxiety, depression, and gastric emptying as predictors of functional dyspepsia: a case-control study. J Psychosom Res. 2010;68(1):73-81.

45. Filipović BF, Randjelovic T, Ille T, Markovic O, Milovanović B, Kovacevic N, et al. Anxiety, personality traits and quality of life in functional dyspepsiA-suffering patients. Eur J Intern Med. 2013;24(1):83-6.

46. Ly HG, Weltens N, Tack J, Van Oudenhove L. Acute anxiety and anxiety disorders are associated with impaired gastric accommodation in patients with functional dyspepsia. Clin Gastroenterol Hepatol. 2015;13(9):1584-91.e3.

47. Pinto-Sanchez MI, Ford AC, Avila CA, Verdu EF, Collins SM, Morgan D, et al. Anxiety and depression increase in a stepwise manner in parallel with multiple FGIDs and symptom severity and frequency. Am J Gastroenterol. 2015;110(7):1038-48.

48. Kindt S, Van Oudenhove L, Mispelon L, Caenepeel P, Arts J, Tack J. Longitudinal and cross-sectional factors associated with long-term clinical course in functional dyspepsia: a 5-year follow-up study. Am J Gastroenterol. 2011;106(2):340-8.

49. Bernersen B, Johnsen R, Straume B. Non-ulcer dyspepsia and peptic ulcer: the distribution in a population and their relation to risk factors. Gut. 1996;38(6):822-5. 
50. Zagari RM, Law GR, Fuccio L, Cennamo V, Gilthorpe MS, Forman D, et al. Epidemiology of functional dyspepsia and subgroups in the Italian general population: an endoscopic study. Gastroenterology. 2010;138(4):1302-11.

51. Olafsdottir LB, Gudjonsson H, Jonsdottir HH, Thjodleifsson B. Natural history of functional dyspepsia: a 10 -year populationbased study. Digestion. 2010;81(1):53-61.

52. Talley NJ, Zinsmeister AR, Schleck CD, Melton LJ, 3rd. Smoking, alcohol, and analgesics in dyspepsia and among dyspepsia subgroups: lack of an association in a community. Gut. 1994;35(5):619-24.

53. Haque M, Wyeth JW, Stace NH, Talley NJ, Green R. Prevalence, severity and associated features of gastro-oesophageal reflux and dyspepsia: a population-based study. N Z Med J. 2000;113(1110): 178-81.

54. Chang FY, Chen PH, Wu TC, Pan WH, Chang HY, Wu SJ, et al. Prevalence of functional gastrointestinal disorders in Taiwan: questionnaire-based survey for adults based on the Rome III criteria. Asia Pac J Clin Nutr. 2012;21(4):594-600.

55. Lacy BE, Weiser KT, Kennedy AT, Crowell MD, Talley NJ. Functional dyspepsia: the economic impact to patients. Aliment Pharmacol Ther. 2013;38(2):170-7.

56. Brook RA, Kleinman NL, Choung RS, Melkonian AK, Smeeding JE, Talley NJ. Functional dyspepsia impacts absenteeism and direct and indirect costs. Clin Gastroenterol Hepatol. 2010;8(6): 498-503.

57. Piessevaux $\mathrm{H}$, de Winter $\mathrm{B}$, Louis $\mathrm{E}$, Muls $\mathrm{V}$, de Looze $\mathrm{D}$, Pelckmans $P$, et al. Dyspeptic symptoms in the general population: a factor and cluster analysis of symptom groupings. Neuro Gastroenterol Motil. 2009;21(4):378-88.

58. Mahadeva S, Ford AC. Clinical and epidemiological differences in functional dyspepsia between the East and the West. Neuro Gastroenterol Motil. 2016;28(2):167-74.

59. Sander GB, Mazzoleni LE, Francesconi CF, Balbinotto G, Mazzoleni F, Wortmann AC, et al. Helicobacter eradication relief of dyspetic symptoms trial investigators. Influence of organic and functional dyspepsia on work productivity: the HEROES-DIP study. Value Health. 2011;14(5 Suppl 1):S126-9.

60. Hantoro IF, Syam AF, Mudjaddid E, Setiati S, Abdullah M. Factors associated with health-related quality of life in patients with functional dyspepsia. Health Qual Life Outcomes. 2018;16(1):83.

61. Aro P, Talley NJ, Agréus L, Johansson SE, Bolling-Sternevald E, Storskrubb T, et al. Functional dyspepsia impairs quality of life in the adult population. Aliment Pharmacol Ther. 2011;33(11):1215-24.

62. Van Oudenhove L, Vandenberghe J, Vos R, Holvoet L, Demyttenaere $\mathrm{K}$, Tack J. Risk factors for impaired health-related quality of life in functional dyspepsia. Aliment Pharmacol Ther. 2011;33(2): 261-74.

63. Tack J, Piessevaux H, Coulie B, Caenepeel P, Janssens J. Role of impaired gastric accommodation to a meal in functional dyspepsia. Gastroenterology. 1998;115:1346-52.

64. Tack J, Caenepeel P, Fischler B, Piessevaux H, Janssens J. Symptoms accosiated with hypersensitivity to gastric distention in functional dyspepsia. Gastroenterology. 2001;121:526-35.

65. Jones MP, Talley NJ, Eslick GD, Dubois D, Tack J. Community subgroups in dyspepsia and their association with weight loss. Am J Gastroenterol. 2008;103(8):2051-60.

66. Tack J, Jones MP, Karamanolis G, Coulie B, Dubois D. Symptom pattern and pathophysiological correlates of weight loss in tertiary-referred functional dyspepsia. Neuro Gastroenterol Motil. 2010;22(1):29-35.

67. Tack J, Caenepeel P, Piessevaux H, Cuomo R, Janssens J. Assessment of meal-induced gastric accommodation by a satiety drinking test in health and in functional dyspepsia. Gut. 2003;52:1271-7.
68. Ford AC, Forman D, Bailey AG, Cook MB, Axon AT, Moayyedi P. Who consults with dyspepsia? Results from a longitudinal 10-yr follow-up study. Am J Gastroenterol. 2007;102(5):957-65.

69. Ahlawat SK, Richard Locke G, Weaver AL, Farmer SA, Yawn BP, Talley NJ. Dyspepsia consulters and patterns of management: a population-based study. Aliment Pharmacol Ther. 2005;22(3):251-9.

70. Westbrook JI, Mclntosh J, Talley NJ. Factors associated with consulting medical or non-medical practitioners for dyspepsia: an australian population-based study. Aliment Pharmacol Ther. 2000;14(12):1581-8.

71. Jones MP, Tack J, Van Oudenhove L, Walker MM, Holtmann G, Koloski NA, et al. Mood and anxiety disorders precede development of functional gastrointestinal disorders in patients but not in the population. Clin Gastroenterol Hepatol. 2017;15(7): 1014-20.

72. Hungin AP, Hill C, Raghunath A. Systematic review: frequency and reasons for consultation for gastro-oesophageal reflux disease and dyspepsia. Aliment Pharmacol Ther. 2009;30(4):331-42.

73. Castillo EJ, Camilleri M, Locke GR, Burton DD, Stephens DA, Geno $\mathrm{DM}$, et al. A community-based, controlled study of the epidemiology and pathophysiology of dyspepsia. Clin Gastroenterol Hepatol. 2004;2(11):985-96.

74. Bisschops R, Karamanolis G, Arts J, Caenepeel P, Verbeke K, Janssens $J$, et al. Relationship between symptoms and ingestion of a meal in functional dyspepsia. Gut. 2008;57(11):1495-503.

75. Mullan A, Kavanagh P, O'Mahony P, Joy T, Gleeson F, Gibney MJ. Food and nutrient intakes and eating patterns in functional and organic dyspepsia. Eur J Clin Nutr. 1994;48(2):97-105.

76. Pilichiewicz AN, Horowitz M, Holtmann GJ, Talley NJ, FeinleBisset C. Relationship between symptoms and dietary patterns in patients with functional dyspepsia. Clin Gastroenterol Hepatol. 2009;7(3):317-22.

77. Carvalho RV, Lorena SL, Almeida JR, Mesquita MA. Food intolerance, diet composition, and eating patterns in functional dyspepsia patients. Dig Dis Sci. 2010;55(1):60-5.

78. Saito YA, Locke GR, 3rd, Weaver AL, Zinsmeister AR, Talley NJ. Diet and functional gastrointestinal disorders: a population-based case-control study. Am J Gastroenterol. 2005;100(12):2743-8.

79. Duncanson KR, Talley NJ, Walker MM, Burrows TL. Food and functional dyspepsia: a systematic review. J Hum Nutr Diet. 2018;31(3):390-407.

80. Malfertheiner P, Megraud F, O'Morain CA, Gisbert JP, Kuipers EJ, Axon AT, et al. European Helicobacter and microbiota study group and consensus panel. Management of Helicobacter pylori infection - the Maastricht V/Florence consensus report. Gut. 2017; 66(1):6-30.

81. Sugano K, Tack J, Kuipers EJ, Graham DY, El-Omar EM, Miura S, et al. Faculty members of Kyoto Global Consensus Conference. Kyoto global consensus report on Helicobacter pylori gastritis. Gut;64:1353-67.

82. Friedman LS. Helicobacter Pylori and nonulcer dyspepsia. NEJM. 1998;339:1928-30.

83. Troncon LEA, Bennett RJM, Ahluwalia NK, Thompson DG. Abnormal distribution of food during gastric emptying in functional dyspepsia patients. Gut. 1994;35:327-32.

84. Gilja OH, Hausken T, Wilhelmsen I, Berstad A. Impaired accommodation of proximal stomach to a meal in functional dyspepsia. Dig Dis Sci. 1996;41:689-96.

85. Salet GAM, Samsom M, Roelofs JMM, van Berge Henegouwen GP, Smout AJPM, Akkermans LMA. Responses to gastric distention in functional dyspepsia. Gut. 1998;42:823-9.

86. Boeckxstaens GE, Hirsch DP, van den Elzen BD, Heisterkamp SH, Tytgat GN. Impaired drinking capacity in patients with functional 
dyspepsia: relationship with proximal stomach function. Gastroenterology. 2001;121(5):1054-63.

87. Bredenoord AJ, Chial HJ, Camilleri M, Mullan BP, Murray JA. Gastric accommodation and emptying in evaluation of patients with upper gastrointestinal symptoms. Clin Gastroenterol Hepatol. 2003;1(4):264-72.

88. Lunding JA, Gilja OH, Hausken T, Bayati A, Mattsson H, Berstad A. Distension-induced gastric accommodation in functional dyspepsia: effect of autonomic manipulation. Neuro Gastroenterol Motil. 2007;19(5):365-75.

89. Steinsvik EK, Hausken T, Gilja OH. The ultrasound meal accommodation test in 509 patients with functional gastrointestinal disorders. Scand J Gastroenterol. 2016 Jul;51(7):788-94.

90. Asano H, Tomita T, Nakamura K, Yamasaki T, Okugawa T, Kondo T, et al. Prevalence of gastric motility disorders in patients with functional dyspepsia. J Neurogastroenterol Motil. 2017;23(3): 392-9.

91. Vanheel H, Carbone F, Valvekens L, Simren M, Tornblom H, Vanuytsel T, et al. Pathophysiological abnormalities in functional dyspepsia subgroups according to the Rome III criteria. Am J Gastroenterol. 2017;112(1):132-40.

92. Mundt MW, Samsom M. Fundal dysaccommodation in functional dyspepsia: heaD-to-head comparison between the barostat and three-dimensional ultrasonographic technique. Gut. 2006;55(12):1725-30.

93. Caballero-Plasencia AM, Muros-Navarro MC, Martín-Ruiz JL, ValenzuelA-Barranco M, de los Reyes-García MC, CasadoCaballero FJ, et al. Dyspeptic symptoms and gastric emptying of solids in patients with functional dyspepsia. Role of Helicobacter pylori infection. Scand J Gastroenterol. 1995;30(8):745-51.

94. Haag S, Talley NJ, Holtmann G. Symptom patterns in functional dyspepsia and irritable bowel syndrome: relationship to disturbances in gastric emptying and response to a nutrient challenge in consulters and non-consulters. Gut. 2004;53(10):1445-51.

95. Pfeiffer A, Aronbayev J, Schmidt T, Wendl B, Pehl C, Kaess H. Gastric emptying, esophageal 24-hour $\mathrm{pH}$ and gastric potential difference measurements in non-ulcer dyspepsia. Gastroenterol Clin Biol. 1992;16(5):395-400.

96. Quartero AO, de Wit NJ, Lodder AC, Numans ME, Smout AJ, Hoes AW. Disturbed soliD-phase gastric emptying in functional dyspepsia: a metA-analysis. Dig Dis Sci. 1998;43(9):2028-33.

97. Stanghellini V, Tosetti C, Paternico A, Barbara G, Morselli-Labate AM, Monetti N, et al. Risk indicators of delayed gastric emptying of solids in patients with functional dyspepsia. Gastroenterology. 1996;110(4):1036-42.

98. Perri F, Clemente R, Festa V, Annese V, Quitadamo M, Rutgeerts P, et al. Patterns of symptoms in functional dyspepsia: role of Helicobacter pylori infection and delayed gastric emptying. Am J Gastroenterol. 1998;93(11):2082-8.

99. Sarnelli G, Caenepeel P, Geypens B, Janssens J, Tack J. Symptoms associated with delayed emptying of solids and liquids in functional dyspepsia. Am J Gastroenterol. 2003;98:783-8.

100. Cuomo R, Sarnelli G, Grasso R, Alfieri M, Niccolai E, Pumpo R, et al. Functional dyspepsia symptoms, gastric emptying and satiety provocative test: analysis of relationships. Scand J Gastroenterol. 2001;36:1030-6.

101. Delgado-Aros S, Camilleri M, Cremonini F, Ferber I, Stephens D, Burton DD. Contributions of gastric volumes and gastric emptying to meal size and postmeal symptoms in functional dyspepsia. Gastroenterology. 2004;127(6):1685-94.

102. Tominaga K, Higuchi K, Ochi M, Kadouchi K, Kawamura E, Tanigawa $\mathrm{T}$, et al. Concurrent assessment of reservoir and emptying of the stomach for dyspepsia patients. Hepatogastroenterology. 2008;55(82-83):744-9.
103. Coffin B, Azpiroz F, Guarner F, Malagelada JR. Selective gastric hypersensitivity and reflex hyporeactivity in functional dyspepsia. Gastroenterology. 1994;107(5):1345-51.

104. Mertz H, Fullerton S, Naliboff B, Mayer EA. Symptoms and visceral perception in severe functional and organic dyspepsia. Gut. 1998;42:814-22.

105. Holtmann G, Gschossmann J, Neufang-Huber J, Gerken G, Talley NJ. Differences in gastric mechanosensory function after repeated ramp distensions in non-consulters with dyspepsia and healthy controls. Gut. 2000;47:332-6.

106. Rhee PL, Kim YH, Son HJ, Kim JJ, Koh KC, Paik SW, et al. Evaluation of individual symptoms acannot predict presence of gastric hypersensitivity in functional dyspepsia. Dig. Dis. Sci. 2000. 2000;45:1680-4.

107. Farré R, Vanheel $H$, Vanuytsel T, Masaoka T, Törnblom H, Simrén $M$, et al. Functional dyspepsia, hypersensitivity to postprandial distention correlates with meal-related symptom severity. Gastroenterology. 2013;145(3):566-73.

108. Simrén M, Törnblom H, Palsson OS, van Tilburg MA, Van Oudenhove L, Tack J, et al. visceral hypersensitivity is associated with GI symptom severity in functional Gl disorders: consistent findings from five different patient cohorts. Gut. 2018;67(2):255-62.

109. Talley NJ, Walker MM, Aro P, Ronkainen J, Storskrubb T, Hindley LA, et al. Non-ulcer dyspepsia and duodenal eosinophilia: an adult endoscopic population-based case-control study. Clin Gastroenterol Hepatol. 2007;5(10):1175-83.

110. Vanheel H, Vicario M, Vanuytsel T, Van Oudenhove L, Martinez C, Keita AV, et al. Impaired duodenal mucosal integrity and low-grade inflammation in functional dyspepsia. Gut. 2014;63(2):262-71.

111. Walker MM, Aggarwal KR, Shim LS, Bassan M, Kalantar JS, Weltman $\mathrm{MD}$, et al. Duodenal eosinophilia and early satiety in functional dyspepsia: confirmation of a positive association in an Australian cohort. J Gastroenterol Hepatol. 2014;29(3):474-9.

112. Cirillo C, Bessissow T, Desmet AS, Vanheel H, Tack J, Vanden Berghe $P$. Evidence for neuronal and structural changes in submucous ganglia of patients with functional dyspepsia. Am J Gastroenterol. 2015;110(8):1205-15.

113. Vanheel H, Vicario M, Boesmans W, Vanuytsel T, Salvo-Romero E, Tack J, et al. Activation of eosinophils and mast cells in functional dyspepsia: an ultrastructural evaluation. Sci Rep. 2018;8(1):5383.

114. Wauters L, Talley NJ, Walker MM, Tack J, Vanuytsel T. Novel concepts in the pathophysiology and treatment of functional dyspepsia. Gut. 2020;69(3):591-600. https://doi.org/10.1136/ gutjnl-2019-318536.

115. Wauters L, Burns G, Ceulemans M, et al. Duodenal inflammation: an emerging target for functional dyspepsia? Expert Opin Ther Targets. 2020;24(6):511-23. https://doi.org/10.1080/14728222. 2020.1752181.

116. Kindt S, van Oudenhove L, Broekaert D, Kasran A, Ceuppens JL, Bossuyt $\mathrm{X}$, et al. Immune dysfunction in patients with functional gastrointestinal disorders. Neuro Gastroenterol Motil. 2009;21(4):389-98.

117. Kindt S, Tertychnyy A, de Hertogh G, Geboes K, Tack J. Intestinal immune activation in presumed post-infectious functional dyspepsia. Neuro Gastroenterol Motil. 2009;21(8):832.e56.

118. Collen MJ, Loebenberg MJ. Basal gastric acid secretion in nonulcer dyspepsia with or without duodenitis. Dig Dis Sci. 1989 Feb;34(2):246-50.

119. Lee KJ, Demarchi B, Demedts I, Sifrim D, Raeymaekers P, Tack J. A pilot study on duodenal acid exposure and its relationship to symptoms in functional dyspepsia with prominent nausea. Am J Gastroenterol. 2004;99:1765-73.

120. Bratten J, Jones MP. Prolonged recording of duodenal acid exposure in patients with functional dyspepsia and controls using a 
radiotelemetry $\mathrm{pH}$ monitoring system. J Clin Gastroenterol. 2009;43(6):527-33.

121. Van den Houte K, Scarpellini E, Verbeure W, Mori H, Schol J, Masuy I, et al. The role of Gl peptides in functional dyspepsia and gastroparesis: a systematic review. Front Psychiatry. 2020;11:172.

122. Pilichiewicz AN, Feltrin KL, Horowitz M, Holtmann G, Wishart JM, Jones $\mathrm{KL}$, et al. Functional dyspepsia is associated with a greater symptomatic response to fat but not carbohydrate, increased fasting and postprandial CCK, and diminished PYY. Am J Gastroenterol. 2008;103(10):2613-23.

123. Chua AS, Bekkering M, Rovati LC, Keeling PW. Clinical efficacy and prokinetic effect of the CCK-A antagonist loxiglumide in nonulcer dyspepsia. Ann N Y Acad Sci. 1994;713:451-3.

124. Feinle C, Meier O, Otto B, D'Amato M, Fried M. Role of duodenal lipid and cholecystokinin A receptors in the pathophysiology of functional dyspepsia. Gut. 2001 Mar;48(3):347-55.

125. Choi YJ, Park YS, Kim N, Kim YS, Lee SM, Lee DH, et al. Gender differences in ghrelin, nociception genes, psychological factors and quality of life in functional dyspepsia. World J Gastroenterol. 2017;23(45):8053-61.

126. Shindo T, Futagami S, Hiratsuka T, Horie A, Hamamoto T, Ueki N, et al. Comparison of gastric emptying and plasma ghrelin levels in patients with functional dyspepsia and non-erosive reflux disease. Digestion. 2009;79(2):65-72.

127. Carbone F, Tack J. Gastroduodenal mechanisms underlying functional gastric disorders. Dig Dis. 2014;32(3):222-9.

128. Fried $M$, Feinle $C$. The role of fat and cholecystokinin in functional dyspepsia. Gut. 2002;51(Suppl 1):i54-7.

129. Samsom M, Verhagen MA, vanBerge Henegouwen GP, Smout AJ. Abnormal clearance of exogenous acid and increased acid sensitivity of the proximal duodenum in dyspeptic patients. Gastroenterology. 1999;116(3):515-20.

130. Schwartz MP, Samsom M, Smout AJ. Chemospecific alterations in duodenal perception and motor response in functional dyspepsia. Am J Gastroenterol. 2001;96(9):2596-602.

131. Zhong L, Shanahan ER, Raj A, Koloski NA, Fletcher L, Morrison M, et al. Dyspepsia and the microbiome: time to focus on the small intestine. Gut. 2017;66(6):1168-9.

132. Nakae H, Tsuda A, Matsuoka T, Mine T, Koga Y. Gastric microbiota in the functional dyspepsia patients treated with probiotic yogurt. BMJ Open Gastroenterol. 2016;3(1).e000109.

133. Andrews PL, Sanger GJ. Abdominal vagal afferent neurones: an important target for the treatment of gastrointestinal dysfunction. Curr Opin Pharmacol. 2002;2(6):650-6.

134. Holtmann G, Goebell H, Jockenhoevel F, Talley NJ. Altered vagal and intestinal mechanosensory function in chronic unexplained dyspepsia. Gut. 1998;42(4):501-6.

135. Manabe N, Nakamura K, Hara M, Imamura H, Kusunoki H, Tanaka $\mathrm{S}$, et al. Impaired gastric response to modified sham feeding in patients with postprandial distress syndrome. Neuro Gastroenterol Motil. 2011;23(3):215-9:e112.

136. Lunding JA, Nordström LM, Haukelid AO, Gilja OH, Berstad A, Hausken T. Vagal activation by sham feeding improves gastric motility in functional dyspepsia. Neuro Gastroenterol Motil. 2008;20(6):618-24.

137. Hjelland IE, Svebak S, Berstad A, Flatabø G, Hausken T. Breathing exercises with vagal biofeedback may benefit patients with functional dyspepsia. Scand J Gastroenterol. 2007;42(9):1054-62.

138. Guo WJ, Yao SK, Zhang YL, Du SY, Wang HF, Yin LJ, et al. Impaired vagal activity to meal in patients with functional dyspepsia and delayed gastric emptying. J Int Med Res. 2018;46(2):792-801.

139. Van Oudenhove L, Vandenberghe J, Dupont P, Geeraerts B, Vos R, Dirix $S$, et al. Abnormal regional brain activity during rest and (anticipated) gastric distension in functional dyspepsia and the role of anxiety: a $\mathrm{H}(2)(15) \mathrm{O}-\mathrm{PET}$ study. Am J Gastroenterol. 2010;105(4):913-24.

140. Liu P, Zeng F, Zhou G, Wang J, Wen H, von Deneen KM, et al. Alterations of the default mode network in functional dyspepsia patients: a resting-state fmri study. Neuro Gastroenterol Motil. 2013;25(6):e382-8.

141. Nan J, Liu J, Mu J, Dun W, Zhang M, Gong Q, et al. Brain-based correlations between psychological factors and functional dyspepsia. J Neurogastroenterol Motil. 2015;21(1):103-10.

142. Tominaga K, Tsumoto C, Ataka S, Mizuno K, Takahashi K, Yamagami $\mathrm{H}$, et al. Regional brain disorders of serotonin neurotransmission are associated with functional dyspepsia. Life Sci. 2015;137:150-7.

143. Ly HG, Ceccarini J, Weltens N, Bormans G, Van Laere K, Tack J, et al. Increased cerebral cannabinoiD-1 receptor availability is a stable feature of functional dyspepsia: a [F]MK-9470 PET study. Psychother Psychosom. 2015;84(3):149-58.

144. Lee IS, Wang H, Chae Y, Preiss H, Enck P. Functional neuroimaging studies in functional dyspepsia patients: a systematic review. Neuro Gastroenterol Motil. 2016;28(6):793-805.

145. Locke GR, 3rd, Zinsmeister AR, Talley NJ, Fett SL, Melton LJ, 3rd. Familial association in adults with functional gastrointestinal disorders. Mayo Clin Proc. 2000;75(9):907-12.

146. Dai F, Liu Y, Shi H, Ge S, Song J, Dong L, et al. Association of genetic variants in GNB3 with functional dyspepsia: a metA-analysis. Dig Dis Sci. 2014 Aug;59(8):1823-30.

147. Song YZ, You HY, Zhu ZH, Wen ZD, Xu HY, Chen BC, et al. The C825T polymorphism of the $G$-protein $\beta 3$ gene as a risk factor for functional dyspepsia: a metA-analysis. Gastroenterol Res Pract. 2016;2016.5037254.

148. Kourikou A, Karamanolis GP, Dimitriadis GD, Triantafyllou K. Gene polymorphisms associated with functional dyspepsia. World J Gastroenterol. 2015;21(25):7672-82.

149. Talley NJ, Vakil NB, Moayyedi P. American gastroenterological association technical review on the evaluation of dyspepsia. Gastroenterology. 2005;129(5):1756-80.

150. Moayyedi P, Lacy BE, Andrews CN, Enns RA, Howden CW, Vakil N. ACG and CAG clinical guideline: management of dyspepsia. Am J Gastroenterol. 2017 Jul;112(7):988-1013.

151. Moayyedi P, Talley NJ, Fennerty MB, Vakil N. Can the clinical history distinguish between organic and functional dyspepsia? J Am Med Assoc. 2006;295(13):1566-76.

152. Dutta AK, Rebekah G, Chowdhury SD, Gangadharan SK, Subramani $\mathrm{Y}$, Sahu MK, et al. A simple pre-endoscopy score for predicting risk of malignancy in patients with dyspepsia: a 5-year prospective study. Dig Dis Sci. 2018 Dec;63(12):3442-7.

153. Feld L, Cifu AS. Management of dyspepsia. J Am Med Assoc. 2018;319(17):1816-7.

154. Duggan AE, Elliott CA, Miller P, Hawkey CJ, Logan RF. Clinical trial: a randomized trial of early endoscopy, Helicobacter pylori testing and empirical therapy for the management of dyspepsia in primary care. Aliment Pharmacol Ther. 2009 Jan;29(1):55-68.

155. Jönsson KA, Gotthard R, Bodemar G, Brodin U. The clinical relevance of endoscopic and histologic inflammation of gastroduodenal mucosa in dyspepsia of unknown origin. Scand J Gastroenterol. 1989;24(4):385-95.

156. Talley NJ. Functional dyspepsia and the Rome criteria: a success story. Neuro Gastroenterol Motil. 2015;27(8):1052-6.

157. Carbone F, Holvoet L, Tack J. Rome III functional dyspepsia subdivision in PDS and EPS: recognizing postprandial symptoms reduces overlap. Neuro Gastroenterol Motil. 2015;27(8):1069-74.

158. Carbone F, Vanuytsel T, Tack J. Analysis of postprandial symptom patterns in subgroups of patients with Rome III or Rome IV functional dyspepsia. Clin Gastroenterol Hepatol. 2020;18(4): 838-46.e3. 
159. Suzuki H, Kusunoki H, Kamiya T, Futagami S, Yamaguchi Y, Nishizawa $\mathrm{T}$, et al. Effect of lansoprazole on the epigastric symptoms of functional dyspepsia (ELF study): a multicentre, prospective, randomized, double-blind, placebo-controlled clinical trial. United Eur Gastroenterol J. 2013;1(6):445-52.

160. Xu S, Wan X, Zheng X, Zhou Y, Song Z, Cheng M, et al. Symptom improvement after helicobacter pylori eradication in patients with functional dyspepsia-a multicenter, randomized, prospective cohort study. Int J Clin Exp Med. 2015;6(9):747-56.

161. Hsu YC, Liou JM, Yang TH, Hsu WL, Lin HJ, Wu HT, et al. Proton pump inhibitor versus prokinetic therapy in patients with functional dyspepsia: is therapeutic response predicted by Rome III subgroups? J Gastroenterol. 2011;46(2):183-90.

162. Kamiya T, Shikano M, Kubota E, Mizoshita T, Wada T, Tanida S, et al. A multicenter randomized trial comparing rabeprazole and itopride in patients with functional dyspepsia in Japan: the NAGOYA study. J Clin Biochem Nutr. 2017;60(2):130-5.

163. Kraag N, Thijs C, Knipschild P. DyspepsiA--how noisy are gallstones? A metA-analysis of epidemiologic studies of biliary pain, dyspeptic symptoms, and food intolerance. Scand J Gastroenterol. 1995;30(5):411-21.

164. Berger MY, van der Velden JJ, Lijmer JG, de Kort H, Prins A, Bohnen AM. Abdominal symptoms: do they predict gallstones? A systematic review. Scand J Gastroenterol. 2000;35(1):70-6.

165. Tack J, Bisschops R, Sarnelli G. Pathophysiology and treatment of functional dyspepsia. Gastroenterology. 2004;127(4):1239-55.

166. Janssen $P$, Harris MS, Jones M, Masaoka T, Farré R, Törnblom H, et al. The relation between symptom improvement and gastric emptying in the treatment of diabetic and idiopathic gastroparesis. Am J Gastroenterol. 2013;108(9):1382-91.

167. Vijayvargiya P, Jameie-Oskooei S, Camilleri M, Chedid V, Erwin PJ, Murad $\mathrm{MH}$. Association between delayed gastric emptying and upper gastrointestinal symptoms: a systematic review and metA -analysis. Gut. 2019;68(5):804-13.

168. Vijayvargiya P, Camilleri M, Chedid V, Mandawat A, Erwin PJ, Murad $\mathrm{MH}$. Effects of promotility agents on gastric emptying and symptoms: a systematic review and metA-analysis. Gastroenterology. 2019;156(6):1650-60.

169. Tack J, Caenepeel P, Arts J, Lee KJ, Sifrim D, Janssens J. Prevalence of acid reflux in functional dyspepsia and its association with symptom profile. Gut. 2005;54(10):1370-6.

170. Gerson LB, Triadafilopoulos G. A prospective study of oesophageal 24-h ambulatory $\mathrm{pH}$ monitoring in patients with functional dyspepsia. Dig Liver Dis. 2005;37(2):87-91.

171. Xiao YL, Peng S, Tao J, Wang AJ, Lin JK, Hu PJ, et al. Prevalence and symptom pattern of pathologic esophageal acid reflux in patients with functional dyspepsia based on the Rome III criteria. Am J Gastroenterol. 2010;105(12):2626-31.

172. Du L, Chen B, Kim JJ, Chen X, Dai N. Micro-inflammation in functional dyspepsia: a systematic review and metA-analysis. Neuro Gastroenterol Motil. 2018;30(4).e13304.

173. Marzio L, Falcucci M, Grossi L, Ciccaglione FA, Malatesta MG, Castellano A, et al. Proximal and distal gastric distension in normal subjects and $\mathrm{H}$. pylori-positive and -negative dyspeptic patients and correlation with symptoms. Dig Dis Sci. 1998;43(12):2757-63.

174. Hjelland IE, Ofstad AP, Narvestad JK, Berstad A, Hausken T. Drink tests in functional dyspepsia: which drink is best? Scand J Gastroenterol. 2004;39:933-72.

175. Jones MP, Hoffman S, Shah D, Patel K, Ebert CC. The water load test: observations from healthy controls and patients with functional dyspepsia. Am J Physiol Gastrointest Liver Physiol. 2003;284: G896-904.

176. Kindt S, Coulie B, Wajs E, Janssens J, Tack J. Reproducibility and symptomatic predictors of a slow nutrient drinking test in health and in functional dyspepsia. Neuro Gastroenterol Motil. 2008;20:320-9.

177. Suzuki H, Moayyedi P. Helicobacter pylori infection in functional dyspepsia. Nat Rev Gastroenterol Hepatol. 2013 Mar;10(3):168-74.

178. No authors listed. Surveillance of gastro-oesophageal reflux disease and dyspepsia in adults: investigation and management; 2019. https://www.nice.org.uk/guidance/cg184

179. Miwa H, Ghoshal UC, Gonlachanvit S, Gwee KA, Ang TL, Chang FY, et al. Asian consensus report on functional dyspepsia. J Neurogastroenterol Motil. 2012 Apr;18(2):150-68.

180. Miwa H, Kusano M, Arisawa T, Oshima T, Kato M, Joh T, et al. Evidence-based clinical practice guidelines for functional dyspepsia. J Gastroenterol. 2015 Feb;50(2):125-39.

181. Wang WH, Huang JQ, Zheng GF, Xia HH, Wong WM, Liu XG, et al. Effects of proton-pump inhibitors on functional dyspepsia: a metA-analysis of randomized placebo-controlled trials. Clin Gastroenterol Hepatol. 2007 Feb;5(2):178-85.

182. Pinto-Sanchez MI, Yuan Y, Hassan A, Bercik P, Moayyedi P. Proton pump inhibitors for functional dyspepsia. Cochrane Database Syst Rev. 2017 Nov 21;11(11).CD011194.

183. Blum AL, Arnold R, Stolte M, Fischer M, Koelz HR. Short course acid suppressive treatment for patients with functional dyspepsia: results depend on Helicobacter pylori status. The Frosch Study Group. Gut. 2000 Oct;47(4):473-80.

184. Dillon JF, Finch PJ, Baxter G. A comparison of lansoprazole vs ranitidine in the treatment of functional ulcer-like dyspepsia as defined by the Rome II criteria. Gut. 2004;53(Suppl VI).A285.

185. Camilleri M, Stanghellini V. Current management strategies and emerging treatments for functional dyspepsia. Nat Rev Gastroenterol Hepatol. 2013 Mar;10(3):187-94.

186. Iwakiri R, Tominaga K, Furuta K, Inamori M, Furuta T, Masuyama $\mathrm{H}$, et al. Randomised clinical trial: rabeprazole improves symptoms in patients with functional dyspepsia in Japan. Aliment Pharmacol Ther. 2013 Oct;38(7):729-40.

187. Pittayanon R, Yuan Y, Bollegala NP, Khanna R, Lacy BE, Andrews $\mathrm{CN}$, et al. Prokinetics for functional dyspepsia: a systematic review and meta-analysis of randomized control trials. Am J Gastroenterol. 2019 Feb;114(2):233-43.

188. Tack J, Camilleri M, Chang L, Chey WD, Galligan JJ, Lacy BE, et al. Systematic review: cardiovascular safety profile of 5-HT(4) agonists developed for gastrointestinal disorders. Aliment Pharmacol Ther. 2012 Apr;35(7):745-67.

189. De Nutte N, Van Ganse W, Witterhulghe M, Defrance P. Relief of epigastric pain in nonulcer dyspepsia: controlled trial of the promotility drug cisapride. Clin Ther. 1989;11(1):62-8.

190. Holtmann G, Talley NJ, Liebregts T, Adam B, Parow C. A placebocontrolled trial of itopride in functional dyspepsia. N Engl J Med. 2006;354(8):832-40.

191. Talley NJ, Tack J, Ptak T, Gupta R, Giguère M. Itopride in functional dyspepsia: results of two phase III multicentre, randomised, double-blind, placebo-controlled trials. Gut. 2008;57(6):740-6.

192. Masuy I, Van Oudenhove L, Tack J. Review article: treatment options for functional dyspepsia. Aliment Pharmacol Ther. 2019;49(9):1134-72.

193. Carbone F, Vandenberghe A, Holvoet L, Piessevaux H, Arts J, Caenepeel $\mathrm{F}$, et al. A double-blind randomized, multicenter, placebo-controlled study of itopride in functional dyspepsia postprandial distress syndrome. Submitted for publication 2020 or Carbone F, Vandenberghe A, Holvoet L, Vanuytsel T, Jones MP, Tack JF. 383-The therapeutic outcome of itopride in functional dyspepsia postprandial distress syndrome: a double-blind randomized, multicenter, placebo-controlled study. Gastroenterology. 2018;154(6):S1-91. 
194. Ford AC, Luthra P, Tack J, Boeckxstaens GE, Moayyedi P, Talley NJ. Efficacy of psychotropic drugs in functional dyspepsia: systematic review and meta-analysis. Gut. 2017;66(3):411-42.

195. Talley NJ, Locke GR, Saito YA, Almazar AE, Bouras EP, Howden $\mathrm{CW}$, et al. Effect of amitriptyline and escitalopram on functional dyspepsia: a multicenter, randomized controlled study. Gastroenterology. 2015 Aug;149(2):340-9.e2.

196. Lacy BE, Saito YA, Camilleri M, Bouras E, DiBaise JK, Herrick $L M$, et al. Effects of antidepressants on gastric function in patients with functional dyspepsia. Am J Gastroenterol. 2018; 113(2):216-24.

197. Cheong PK, Ford AC, Cheung CKY, Ching JYL, Chan Y, Sung JJY, et al. Low-dose imipramine for refractory functional dyspepsia: a randomised, double-blind, placebo-controlled trial. Lancet Gastroenterol Hepatol. 2018;3(12):837-44.

198. Tan VP, Cheung TK, Wong WM, Pang R, Wong BC. Treatment of functional dyspepsia with sertraline: a double-blind randomized placebo-controlled pilot study. World J Gastroenterol. 2012;18(42):6127-33.

199. van Kerkhoven LA, Laheij RJ, Aparicio N, De Boer WA, Van den Hazel S, Tan AC, et al. Effect of the antidepressant venlafaxine in functional dyspepsia: a randomized, double-blind, placebocontrolled trial. Clin Gastroenterol Hepatol. 2008;6(7):746-52.

200. Tack J, Ly HG, Carbone F, Vanheel H, Vanuytsel T, Holvoet L, et al. Efficacy of mirtazapine in patients with functional dyspepsia and weight loss. Clin Gastroenterol Hepatol. 2016;14(3): 385-92.e4.

201. Jiang SM, Jia L, Liu J, Shi MM, Xu MZ. Beneficial effects of antidepressant mirtazapine in functional dyspepsia patients with weight loss. World J Gastroenterol. 2016;22(22):5260-6.

202. Miwa H, Nagahara A, Tominaga K, Yokoyama T, Sawada $Y$, Inoue $\mathrm{K}$, et al. Efficacy of the 5-HT1A agonist tandospirone citrate in improving symptoms of patients with functional dyspepsia: a randomized controlled trial. Am J Gastroenterol. 2009;104(11):2779-87.

203. Tack J, van den ElzenB, Tytgat G, Wajs E, van Nueten L, de Ridder $\mathrm{F}$, et al. placebo-controlled trial of the 5-HT agonist R-137696 on symptoms, visceral hypersensitivity and on impaired accommodation in functional dyspepsia. Neuro Gastroenterol Motil. 2009;21(6):619-26.e23-4.

204. Tack J, Janssen P, Masaoka T, Farré R, Van Oudenhove L. Efficacy of buspirone, a fundus-relaxing drug, in patients with functional dyspepsia. Clin Gastroenterol Hepatol. 2012;10(11):1239-45.

205. Van Oudenhove L, Kindt S, Vos R, Coulie B, Tack J. Influence of buspirone on gastric sensorimotor function in man. Aliment Pharmacol Ther. 2008;28(11-12):1326-33.

206. Melzer J, Rösch W, Reichling J, Brignoli R, Saller R. MetA-analysis: phytotherapy of functional dyspepsia with the herbal drug preparation STW 5 (Iberogast). Aliment Pharmacol Ther. 2004;20(1112):1279-87.

207. Koretz RL, Rotblatt M. Complementary and alternative medicine in gastroenterology: the good, the bad, and the ugly. Clin Gastroenterol Hepatol. 2004;2(11):957-67.

208. Li J, Lv L, Zhang J, Xu L, Zeng E, Zhang Z, et al. A combination of peppermint oil and caraway oil for the treatment of functional dyspepsia: a systematic review and meta-analysis. Evid Based Complement Alternat Med. 2019;2019:7654947.

209. Hoshino N, Nishizaki D, Hida K, Obama K, Sakai Y. Rikkunshito for upper gastrointestinal symptoms: a systematic review and metaanalysis. Complement Ther Med. 2019;42:255-63.

210. Chu MHK, Wu IXY, Ho RST, Wong CHL, Zhang AL, Zhang Y, et al. Chinese herbal medicine for functional dyspepsia: systematic review of systematic reviews. Therap Adv Gastroenterol. 2018;11.1756284818785573.
211. Tan VP, Liu KS, Lam FY, Hung IF, Yuen MF, Leung WK. Randomised clinical trial: rifaximin versus placebo for the treatment of functional dyspepsia. Aliment Pharmacol Ther. 2017;45(6):767-76.

212. Calvert EL, Houghton LA, Cooper P, Morris J, Whorwell PJ. Longterm improvement in functional dyspepsia using hypnotherapy. Gastroenterology. 2002 Dec;123(6):1778-85.

213. Haug TT, Wilhelmsen I, Svebak S, Berstad A, Ursin H. Psychotherapy in functional dyspepsia. J Psychosom Res. 1994 Oct;38(7):735-44.

214. Haag S, Senf W, Tagay S, Langkafel M, Braun-Lang U, Pietsch A, et al. Is there a benefit from intensified medical and psychological interventions in patients with functional dyspepsia not responding to conventional therapy? Aliment Pharmacol Ther. 2007;25(8):973-86.

215. Kim KN, Chung SY, Cho SH. Efficacy of acupuncture treatment for functional dyspepsia: a systematic review and meta-analysis. Complement Ther Med. 2015;23(6):759-66.

216. Zhou W, Su J, Zhang H. Efficacy and safety of acupuncture for the treatment of functional dyspepsia: meta-analysis. J Altern Complement Med. 2016;22(5):380-9.

217. Ho RST, Chung VCH, Wong CHL, Wu JCY, Wong SYS, Wu IXY. Acupuncture and related therapies used as add-on or alternative to prokinetics for functional dyspepsia: overview of systematic reviews and network meta-analysis. Sci Rep. 2017;7(1):10320.

218. Zheng H, Xu J, Sun X, Zeng F, Li Y, Wu X, et al. Electroacupuncture for patients with refractory functional dyspepsia: a randomized controlled trial. Neuro Gastroenterol Motil. 2018;30(7).e13316.

219. Aucoin M, Lalonde-Parsi MJ, Cooley K. Mindfulness-based therapies in the treatment of functional gastrointestinal disorders: a metaanalysis. Evid Based Complement Alternat Med. 2014;2014: 140724.

220. Vandenbroucke K, Kindt S, Demedts I, Tack J. Outcome of percutaneous jejunal feeding tube placement for refractory idophatic severe gatroparesis: a retrospective review. Acta Gastro-Enterol Belg. 2006;69:D14. (abstract).

221. Quartero AO, Numans ME, Post MW, de Melker RA, de Wit NJ. One-year prognosis of primary care dyspepsia: predictive value of symptom pattern, Helicobacter pylori and GP management. Eur J Gastroenterol Hepatol. 2002;14(1):55-60.

222. Halder SL, Locke GR, 3rd, Schleck CD, Zinsmeister AR, Melton LJ, 3rd, Talley NJ. Natural history of functional gastrointestinal disorders: a 12-year longitudinal population-based study. Gastroenterology. 2007;133(3):799-807.

223. Olafsdottir LB, Gudjonsson H, Jonsdottir HH, Bjornsson E, Thjodleifsson B. Natural history of functional gastrointestinal disorders: comparison of two longitudinal population-based studies. Dig Liver Dis. 2012;44(3):211-7.

224. Chang JY, Locke GR, 3rd, McNally MA, Halder SL, Schleck CD, Zinsmeister AR, et al. Impact of functional gastrointestinal disorders on survival in the community. Am J Gastroenterol. 2010;105(4):822-32.

225. Ford AC, Forman D, Bailey AG, Axon AT, Moayyedi P. Fluctuation of gastrointestinal symptoms in the community: a 10-year longitudinal follow-up study. Aliment Pharmacol Ther. 2008;28(8):1013-20.

How to cite this article: Wauters L, Dickman R, Drug V, et al. United European Gastroenterology (UEG) and European Society for Neurogastroenterology and Motility (ESNM) consensus on functional dyspepsia. United European Gastroenterol J. 2021;9:307-331. https://doi.org/10.1002/ ueg2.12061 